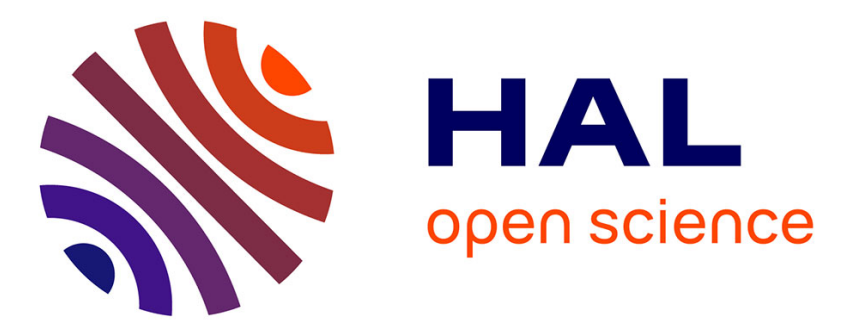

\title{
The NRTL-PRA group contribution EoS for the simultaneous prediction of LLE, VLE and hE of hydrocarbon mixtures with associating compounds
}

Evelyne Neau, Isabelle Raspo, Joan Escandell

\section{- To cite this version:}

Evelyne Neau, Isabelle Raspo, Joan Escandell. The NRTL-PRA group contribution EoS for the simultaneous prediction of LLE, VLE and hE of hydrocarbon mixtures with associating compounds. Fluid Phase Equilibria, 2016, 427, pp.126-142. 10.1016/j.fluid.2016.06.035 . hal-01369874

\section{HAL Id: hal-01369874 https://hal.science/hal-01369874}

Submitted on 6 Apr 2017

HAL is a multi-disciplinary open access archive for the deposit and dissemination of scientific research documents, whether they are published or not. The documents may come from teaching and research institutions in France or abroad, or from public or private research centers.
L'archive ouverte pluridisciplinaire $\mathbf{H A L}$, est destinée au dépôt et à la diffusion de documents scientifiques de niveau recherche, publiés ou non, émanant des établissements d'enseignement et de recherche français ou étrangers, des laboratoires publics ou privés. 


\title{
The NRTL-PRA group contribution EoS for the simultaneous prediction of LLE, VLE and $h^{E}$ of hydrocarbon mixtures with associating compounds
}

\author{
Evelyne Neau $^{\mathrm{a}}$, Isabelle Raspo ${ }^{\mathrm{b}}$, Joan Escandell $^{\mathrm{a}}$ \\ aAix Marseille Univ, CNRS, Centrale Marseille, M2P2, Faculté des Sciences de Luminy, Marseille, France \\ ${ }^{\mathrm{b}}$ Aix Marseille Univ, CNRS, Centrale Marseille, M2P2, Marseille, France
}

\begin{abstract}
The goal of this study is to propose a modification of the NRTL-PR EoS for the prediction of phase equilibria and excess enthalpies in mixtures containing methanol with hydrocarbons; indeed, with these systems, the original equation is confronted to many difficulties arising from the simultaneous prediction of liquid-liquid equilibria together with vapor-liquid and enthalpy data. For this purpose, an additional term is included in the EoS excess Gibbs energy, $g_{E o S}^{E}$, of the Peng-Robinson equation to account for the self-association of methanol. The resulting NRTL-PRA EoS is successfully used for the prediction of both liquid-liquid and vapor-liquid equilibria, as well as excess enthalpies, in mixtures of methanol with hydrocarbons, light gases and associating compounds. Results are comparable to those obtained with other predictive EoS (VTPR and SAFT), but with the main advantage to predict all thermodynamic properties with a simple cubic equation.
\end{abstract}

Keywords: Phase equilibria; EoS/G ${ }^{\mathrm{E}}$ approach; NRTL-PRA EoS; Group contribution; Associating compounds; Methanol.

\section{Introduction}

Formation of gas hydrates is a major problem in offshore petroleum exploitations since it can lead to pipeline obstructions with heavy consequences; this problem is commonly prevented by injecting an inhibitor, mostly methanol. Therefore an accurate prediction of phase equilibria in mixtures containing methanol with hydrocarbons is of great interest for petroleum industry. The major difficulty arises from the simultaneous representation of liquid-liquid (LLE) data together with vaporliquid equilibria (VLE) and excess enthalpies $\left(\mathrm{h}^{\mathrm{E}}\right)$. Up to now, two approaches were considered by chemical engineers to solve this problem: first, the predictive cubic VTPR EoS [1], even if it is known to provide "not very satisfactory" liquid-liquid predictions; second, the CPA [2] and SAFT type equations (PC-SAFT [2-5], GC-PC-SAFT [6], SAFT- $\gamma$ Mie [7], GCA [8]), even if none of these models gives information about the representation of excess enthalpies $h^{E}$ and if few of them (GC-PCSAFT, SAFT- $\gamma$ Mie and GCA EoS) are totally predictive.

The present work is based on the NRTL-PR EoS $[9,10]$ previously developed in the "EoS/g" formalism [11] by using the generalized NRTL Gibbs energy [12] for the EoS excess Gibbs energy, $g_{E o S}^{E}$, coupled with the Peng-Robinson equation of state [13]. The NRTL-PR EoS is both: quite 
simple, since it remains a cubic EoS, and totally predictive, thanks to interaction energy parameters estimated through group contributions. As was shown in [9] and [10], it provides very good results for VLE and $\mathrm{h}^{\mathrm{E}}$ of hydrocarbon mixtures, but also for VLE and LLE of systems including associating compounds, namely water or ethylene glycol, with hydrocarbons.

However, for water-hydrocarbon or ethylene glycol-hydrocarbon mixtures, the main success of the NRTL-PR modeling, using only asymmetrical group interaction parameters between components $K$ and $L\left(\Gamma_{L K} \neq \Gamma_{K L}\right)$, is due to the fact that experimental data concern only one kind of phase equilibria (VLE or LLE). This statement is illustrated in Fig.1 which represents, for the methanol-hexane system, the variation of the EoS excess Gibbs energy with respect to temperature; as for most of binary methanol-paraffin mixtures, the LLE and VLE diagrams are rather symmetric, so that Fig.1 only reports the evolution of $g_{E S S}^{E} / R T$ for equimolar mixtures $\left(x_{1}=0.5\right)$. For this type of mixtures, it is also well known that demixings observed in the LLE domain satisfy the following condition: $g_{E O S}^{E}\left(x_{1}=0.5\right) / R T \geq 0.5$; figure $1 \mathrm{a}$, which represents the variation of this function with parameters determined from LLE data only, shows that, in this domain, namely for $T<308 \mathrm{~K}$ for methanolhexane, $g_{E o S}^{E} / R T$ is actually greater than 0.5 ; however, this modeling predicts, in the VLE domain, a "too fast decrease" of the excess function compared to the evolution expected in Fig.1b, when parameters are determined from VLE data only.

As suggested by the above analysis, the modeling of methanol-hydrocarbon systems which requires the simultaneous representation of LLE and VLE should be more complex. For this purpose, a modification of the NRTL-PR equation is proposed in the present paper. The new EoS, named NRTL-PRA (NRTL-PR with Association) includes an additional term in the EoS excess Gibbs energy of the Peng-Robinson equation to account for the self-association of methanol; the generalized NRTL model being especially adapted to the prediction of liquid phase equilibria (as indicated by its name « Non Random Two Liquids »), the purpose of this additional term is mainly the improvement of predicted VLE and excess enthalpies $\mathrm{h}^{\mathrm{E}}$. Thus, always for the system methanol-hexane, Fig.1c represents the variation of the $g_{E o S}^{E} / R T$ function calculated from the new NRTL-PRA EoS with parameters determined on both VLE and LLE data; the improvement of the variation of the global EoS excess function in the whole temperature range, due to the introduction of this additional term, is obvious.

This paper develops the fundamental bases of the NRTL-PRA EoS and details the extension of the group contributions to methanol with hydrocarbons. The new equation is applied to the prediction of phase equilibria and excess enthalpies of mixtures containing methanol with paraffins, cycloalkanes, aromatics, permanent gases, water and ethylene glycol. It is first compared with the original NRTLPR EoS, in order to valid the behavior of both equations previously described in Fig. 1 for the methanol-hexane system. The NRTL-PRA group contribution EoS is then compared with literature predictive equations: the cubic VTPR EoS and SAFT type equations. We show that results obtained with the proposed EoS are comparable to those provided by the two other literature predictive EoS, but with the main advantage to predict all thermodynamic properties with a simple cubic equation. 


\section{The NRTL-PRA EoS}

The equation is based on the Peng-Robinson equation of state [13]:

$$
P=\frac{R T}{v-b}-\frac{a}{v^{2}+2 b v-b^{2}}
$$

in which the covolume $b$ is calculated by $b=\sum_{i} x_{i} b_{i}$ and the attractive term $a$ is estimated in the $\mathrm{EoS} / \mathrm{g}^{\mathrm{E}}$ formalism using the generalized reference state [14]:

$$
\alpha=\frac{a}{b R T}=\sum_{i} x_{i} \frac{a_{i}}{b_{i} R T}-\frac{1}{0.53}\left[\frac{g_{E o S}^{E}}{R T}\right]
$$

with: $\quad g_{E o S}^{E}=g^{E}-R T \sum_{i} x_{i} \ln \frac{r_{i}}{r} \quad, \quad r=\sum_{i} r_{i}$

where, $r_{i}$ is the volume area factor.

In Eq. (3), the excess Gibbs energy $g^{E}$ is expressed with the generalized NRTL model [12] modified, by means of the term $g_{d i s s}^{E}$, to take account of the self-association of methanol:

$$
g^{E}=g_{\text {diss }}^{E}+g_{\text {res }}^{E}+g_{\text {comb }}^{E}
$$

Since, $g_{\text {comb }}^{E}=R T \sum_{i} x_{i} \ln \left(r_{i} / r\right)$, Eqs. (3) and (4) lead to the final expression of the EoS excess Gibbs energy:

$$
g_{E o S}^{E}=g_{\text {diss }}^{E}+g_{\text {res }}^{E}
$$

It is worth noting that:

- the additional term $g_{\text {diss }}^{E}$ only accounts for the number of interactions between associating components $i$ (asso) and their decrease, during mixings with other components $j$. Indeed, Fig. 2 shows that interactions between methanol molecules $i$ and other mixture compounds $j$ tend to replace the initial interactions between pure methanol molecules, reducing thus the self-association of this compound.

- the residual term $g_{\text {res }}^{E}$ estimates the variation of the interaction energies between molecules $i$ and $j$ with respect to mixings.

\section{1- Dissociation excess Gibbs energy $g_{d i s s}^{E}$}

The dissociation excess Gibbs energy in Eq. (5) is expressed according to :

$$
g_{\text {diss }}^{E}=g_{\text {diss }}^{M}=g_{\text {polym }}-\sum_{i=i(\text { asso })} x_{i} g_{\text {polym }, i}^{\left(x_{i}=1\right)}
$$


where, $g_{\text {polym }}$ and $g_{\text {polym }, i}^{\left(x_{i}=1\right)}$ represent the molar Gibbs energies required for the formation of polymers, respectively in mixtures and in pure components $i$ (asso). The self-association of methanol is described according to the CRG (Chemical-Reticular-Group) model developed by Neau et al. for low pressure phase equilibria [15]:

$$
A_{i 1}+A_{i(k-1)}=A_{i k} \quad\left(\Delta G_{i}^{0}\right)
$$

Assuming that the standard free enthalpy of formation of one hydrogen bond $\Delta G_{i}^{0}$ is independent on the polymer size, Eq. (7) can also be expressed as: $k A_{i 1}=A_{i k}$ with a free enthalpy of formation equal to : $(k-1) \Delta G_{i}^{0}$.

Knowing that the Gibbs energy, $\Delta G_{i}^{0}$, required for the formation of one hydrogen bond is simultaneously associated with the energy, $E_{i i}^{0}$, released by the breaking-off of one interaction between two monomer molecules, the Gibbs energies $g_{\text {polym }}$ and $g_{\text {polym }, i}^{\left(x_{i}=1\right)}$ are expressed as:

$$
g_{\text {polym }}=\sum_{k} X_{i k}(k-1) E_{i(\text { asso })}^{0} \quad, \quad g_{\text {polym }, i}^{\left(x_{i}=1\right)}=\sum_{k} X_{i k}^{\left(x_{i}=1\right)}(k-1) E_{i(\text { asso })}^{0}
$$

with:

$E_{i(\text { asso })}^{0}=\Delta G_{i}^{0}-E_{i i}^{0}, \quad$ and: $\quad E_{i i}^{0}=-(2 / z) E_{i i}, \quad(z=10)$

where, $X_{i k}$ and $X_{i k}^{\left(x_{i}=1\right)}$ are the mole fractions of polymers $k$, respectively in the mixture and in the pure component; $E_{i(\text { asso })}^{0}$ is the global Gibbs energy involved by the formation of one polymer (assuming, as in the original paper [12], that the binary interaction $E_{i i}$ is the configurational energy of $z / 2$ pair interactions $(i-i))$.

Finally, taking account of Eqs. (A-1)-(A-2) in Appendix A, the final expression of $g_{\text {diss }}^{E}$ is:

$$
g_{\text {diss }}^{E}=\sum_{i=i(\text { asso })}\left(x_{i} X_{i}^{\left(x_{i}=1\right)}-X_{i}\right) E_{i(\text { asso })}^{0}
$$

Table 1 resumes the main relations concerning the "dissociation excess Gibbs energy $g_{\text {diss }}^{E}$ ". It is worth noting that the introduction of the association term in the original NRTL-PR EoS implies two major modifications: first, the estimation of new model parameters, second, the estimation of the global mole fractions of polymers, $X_{i}$. These points are described below.

(1) - Estimation of new model parameters. As described in part (b) of table 1, the specific parameters for methanol are:

- the parameters of the Soave function, expressed according to the method previously developed [24] for associating compounds and the UNIFAC subgroup parameters [22,23] ; 
- the free enthalpy of formation of one hydrogen bond, $\Delta G_{i}^{0}$, calculated from the literature experimental data of enthalpy and entropy of association at $T_{0}=298.15 \mathrm{~K}$, assuming a variation type: $\Delta G_{i}^{0}=\left(a+b\left(T_{0} / T-1\right)\right)$ similar to the one proposed in Eq. (20); for methanol, literature data [1621] led to: $\Delta H_{i\left(T_{0}\right)}^{0}=a+b=-17000 \mathrm{~J} \cdot \mathrm{mol}^{-1}, \Delta S_{i\left(T_{0}\right)}^{0}=b / T_{0}=-21.5 \mathrm{~J} \cdot \mathrm{K}^{-1} \cdot \mathrm{mol}^{-1}$

- $E_{i(\text { asso })}^{0}$ expressed from Eq. (9), by calculating the energy, $E_{i i}^{0}$, between two methanol molecules from the group contribution parameters described in table 3.

(2) - Estimation of the global mole fractions of polymers, $X_{i}$. The global mole fractions of polymers, $X_{i}$, can easily be estimated from the global mole fractions $x_{i}$ by means of the intermediate variables $X_{i 1}$ (mole fraction of monomers) and $K_{i}$ (the "pseudo equilibrium constant"). However, the "key" point of the modeling remains the estimation of $K_{i}$ with respect to mole fractions $x_{i}$.

Assuming that $K_{i}^{0}$ is the association equilibrium constant of the polymerization reaction (Eq. (7)), it can be expressed, with respect to the polymer mole fractions, as:

$$
K_{i}^{0}=\exp \left(-\Delta G_{i}^{0} / R T\right)=\left(\frac{X_{i k}}{X_{i 1} X_{i(k-1)}}\right) \operatorname{gam}_{i} \quad \text { with: } \quad \operatorname{gam}_{i}=\left(\frac{\gamma_{i k}}{\gamma_{i 1} \gamma_{i(k-1)}}\right)
$$

where, $\gamma_{i k}$ represent the activity coefficients of polymers $k$ in the mixture. However, these quantities are not available from the model, so that some assumptions are required:

- $\gamma_{i k} \approx \gamma_{i(k-1)}$

- the activity coefficient $\gamma_{i 1}$ of the monomer is estimated from a "combinatorial term of Flory type": $\ln \gamma_{i 1}=\ln \left(\sigma_{i 1} / \sigma\right)$, with : $\sigma=\sum_{m} x_{m} \sigma_{m}$ using generalized expressions of the volume factors $\sigma_{m}$.

The ratio of the activity coefficients in Eq. (11) then reduces to $\operatorname{gam}_{i} \sim 1 / \gamma_{i 1} \sim \sigma / \sigma_{i 1}$, which allows us to express the "pseudo equilibrium constant $K_{i}$ " associated with the polymerization reaction (Eq. (7)) as follows:

$$
K_{i}=\frac{X_{i k}}{X_{i 1} X_{i(k-1)}}=\exp \left(-\Delta G_{i}^{0} / R T\right) / g a m_{i}
$$

where :

$$
\operatorname{gam}_{i}=x_{i}+\sum_{m \neq i(\text { asso })} x_{m}\left(\sigma_{m, i} / \sigma_{i}\right) \quad \text { with }: \sigma_{m, i}=r_{m, i}\left(P_{i}-P_{m}\right)
$$

Parameters introduced in Eq. (13) are the following:

- Polarity parameters $P_{m}$ : they are equal to 1 for polar or associating compounds (water, ethylene glycol, methanol) and 0 in all the other cases. According to Appendix A, a value close to 1 allows predicting "totally miscible" mixings of methanol with water or ethylene glycol, without requiring a "new" modeling of the other associating components. 
- Structural parameters $\sigma_{m, i}$ : they replace the "classical" volume factor estimated from the UNIFAC subgroups [22,23] and account for "stereochemistry" and "chain length" effects; they are estimated according to:

$$
r_{m, i}=\sum_{k} v_{m k} R_{k} S_{k, i}
$$

where, $v_{m k}$ is the number of subgroup $k$ in the molecule $m, R_{k}$ is the UNIFAC volume parameter of subgroup $k[22,23]$ and $S_{k, i}$ is the stereochemistry parameter of group $k$ in the presence of the associating component $i$.

As confirmed by Appendix A, small values of structural parameters $\sigma_{m, i}$ allow a better "miscibility" of components $m$ with methanol, while higher values lead to less miscible mixtures, the critical demixing temperatures of which increase with the molecular size of compound $m$.

The group contribution values of the $S_{k, i}$ parameters are given in Table 2; they were chosen in order to obtain quite miscible mixings with "light gases" or "aromatics" and increased immiscibility in systems containing "cycloalkanes" or "n-paraffins" of increasing sizes (the negative values of $S_{k, i}$ for the $\mathrm{CH}$ and C paraffinic groups take account of the "real" decrease of the molar size of substituted paraffins compared to n-paraffins). The values of the UNIFAC parameters $R_{k}$ and $Q_{k}$ are also reported in Table 2.

\section{2- Residual excess Gibbs energy $g_{r e s}^{E}$}

As for the NRTL-PR EoS, the residual part of the excess Gibbs energy is defined by:

$$
g_{\text {res }}^{E}=\sum_{i} x_{i} q_{i} \sum_{j} \frac{x_{j} q_{j} G_{j i}}{\sum_{m} x_{m} q_{m} G_{m i}} \Gamma_{j i} \quad, \quad G_{j i}=\exp \left(\Gamma_{j i} / R T\right)
$$

but, describing, for the "associating" component $i$, the "reduced" number of external interactions with other mixture components $j$ according to :

$$
q_{i}=q_{i 1}-\left(1-X_{i} / x_{i}\right) /(2 / z)
$$

In the above relation, $q_{i 1} z$ is the number of external contacts for one mole of monomer component $i$ (non-associated); assuming, as developed in the previous section, that one hydrogen bond leads to a decrease of two external contacts for two molecules, $\left(1-X_{i} / x_{i}\right) / 2$ represents the "loss" of external contacts $\Gamma_{j i}$ between the associating component $i$ (asso) and other components $j$ of the mixture.

As in the original EoS, surface area factors $q_{i}$ or $q_{i 1}$ in Eqs. $(15,16)$ are estimated from the UNIFAC subgroups $Q_{k}$ [22,23]:

$$
q_{i 1}=\sum_{k} v_{i k} Q_{k}
$$


Concerning the modeling of "methanol" in terms of group contributions, we have chosen to represent this molecule as the sum of a " $\mathrm{CH}_{3}$ " group and the hydroxyl "OH" group, rather than as a single " $\mathrm{CH}_{4} \mathrm{O}$ " functional group; the extrapolation to higher alcohols will therefore only require the introduction of "new" hydroxyl "OH" groups.

The binary interaction parameters $\Gamma_{j i}$ in Eq. (15) are always estimated with the original group contribution method:

$$
\Gamma_{j i}=\sum_{K} \theta_{i K} \sum_{L}\left(\theta_{j L}-\theta_{i L}\right) \Gamma_{L K} \quad, \quad \Gamma_{K K}=0
$$

where $\theta_{i K}$ is the probability that a contact from a molecule $i$ involves a main group $K$ :

$$
\theta_{i K}=\sum_{k} v_{i k(K)} \frac{Q_{k}}{q_{i}}
$$

with $v_{i k(K)}$ the number of subgroup $k$ belonging to the main group $K$ in a molecule $i$.

As in [9,10], the group interaction parameters $\Gamma_{L K}$ are assumed to be symmetric $\left(\Gamma_{K L}=\Gamma_{L K}\right)$, except if one of these groups is " $\mathrm{H}_{2} \mathrm{O}$ " for water, "MEG" for ethylene glycol or "OH" for methanol. In the original NRTL-PR EoS, it was assumed that a linear dependence of $\Gamma_{L K}$ with respect to $T_{0} / T$, with $T_{0}=298.15 \mathrm{~K}$, was sufficient to get reliable representation of phase equilibria in a large range of temperatures. However, for mixtures of polar or associating compounds, namely methanolwater and methanol-ethylene glycol, we observed that the introduction of an additional term with respect to temperature strongly improved predictions of excess enthalpies. The original dependence of $\Gamma_{L K}[9,10]$ was therefore generalized as follows:

$$
\Gamma_{L K}=\Gamma_{L K}^{(0)}+\Gamma_{L K}^{(1)}\left(\frac{T_{0}}{T}-1\right)+\Gamma_{L K}^{(2)}\left(\frac{T}{T_{0}}-1\right)
$$

The new values of parameters $\Gamma_{L K}^{(0)}, \Gamma_{L K}^{(1)}$ are given in Tables $3 \mathrm{a}$ and $3 \mathrm{~b}$ for "OH" with all "hydrocarbon groups", "light gases" and "associating components", like water or MEG; for these last components, the additional group parameters $\Gamma_{L K}^{(2)}$ are also reported in Table $3 \mathrm{c}$.

\section{3- Pure component parameters estimation}

The attractive term $a_{i}$ and the covolume $b_{i}$ in Eq. (2) are estimated from the critical temperature and pressure, $T_{c i}$ and $P_{c i}$ respectively, by the formulae:

$$
a_{i}=0.45723553 \frac{R^{2} T_{c_{i}}^{2}}{P_{c_{i}}} f\left(T_{r}\right), b_{i}=0.07779607 \frac{R T_{c_{i}}}{P_{c_{i}}}
$$

where $T_{r}$ is the reduced temperature, $T_{r}=T / T_{c_{i}}$, and $f\left(T_{r}\right)$ is the generalized Soave function [24]: 


$$
f\left(T_{r}\right)=\left[1+m\left(1-T_{r}^{\gamma}\right)\right]^{2}
$$

For hydrocarbons and non associating compounds, we still consider the original Soave function [25] corresponding to $\gamma=0.5$ with the parameter $m$ correlated to the acentric factor $\omega$ through the generalized expression proposed by Robinson and Peng [26]:

$$
\begin{array}{ll}
m=0.37464+1.54226 \omega-0.26992 \omega^{2} & \text { if } \quad \omega \leq 0.49 \\
m=0.379642+1.48503 \omega-0.164423 \omega^{2}+0.016666 \omega^{3} & \text { if } \quad \omega>0.49
\end{array}
$$

On the other hand, for associating compounds, $\gamma$ and $m$ parameters are estimated with the values previously proposed in [24] to improve vapor pressure representations $(\gamma=0.65, m=0.6864$ for water and $\gamma=0.9, m=0.6969$ for methanol).

\section{Results and discussion}

The NRTL-PRA group contribution parameters reported in Tables 3a, 3b and 3c were obtained by correlating literature experimental data reported in Table 4; these data can be divided into two sets:

- the first one refers to binary mixtures containing VLE, LLE and $\mathrm{h}^{\mathrm{E}}$ data, such as systems containing methanol with : n-paraffins, from propane to dodecane, substituted paraffins, from 2-methylpropane to 2,2,4-trimethylpentane, cycloalkanes, from cyclopentane to cyclooctane, and substituted cycloalkanes, from methylcyclopentane to methylcyclohexane.

- The second set concerns totally miscible systems with VLE and $\mathrm{h}^{\mathrm{E}}$ data only, namely mixtures of methanol with : aromatics, including benzene and substituted compounds from toluene to 1,3,5trimethylbenzene, light gases, like methane, ethane, carbon dioxide, nitrogen and hydrogen sulfide, and associating compounds, namely water and ethylene glycol.

The most significant results obtained for the prediction of phase equilibria and enthalpies in mixtures containing methanol with hydrocarbons, gases and associating components are reported in this section. First, the predictions obtained with the proposed NRTL-PRA EoS are compared with the results provided by the original NRTL-PR EoS. The NRTL-PRA group contribution EoS is then compared with two literature predictive equations: the cubic VTPR EoS and the SAFT type equations.

\section{1- Influence of the association term for the prediction of $V L E, h^{E}$ and $L L E$}

The aim of this section is to evidence the need of taking into account the dissociation of methanol during mixings with hydrocarbons, especially with paraffins and cycloalkanes. For this purpose, a group contribution method was specially developed with the original NRTL-PR equation; deviations thus obtained are compared with those of the NRTL-PRA EoS. Results are reported in Table 4 according to the type of experimental data. 
- Mixtures of methanol with paraffins and cycloalkanes: VLE, $h^{E}$ and LLE data (Table $4 a$ ). As for all mixtures containing liquid-liquid data, deviations on the mole fractions of the two phases should be considered with great caution, especially when the modeling overestimates the critical mixing temperature; in this situation, the resulting deviations on pressure, for isothermal VLE, and on enthalpies may be questionable. However, in the present case, results for VLE and LLE are not questionable: global deviations obtained with the NRTL-PR equation on pressure, for isothermal VLE, and on the mole fractions $x_{1}$ and $x_{2}$ in the two phases, for LLE, are nearly three times larger than those predicted by the NRTL-PRA model. Concerning $\mathrm{h}^{\mathrm{E}}$, the two models "seem" to provide equivalent results, which does "not mean better" predictions, as is shown with the analysis of the results presented below in Fig. 3.

Figure 3 compares the modelings of methanol-hexane (Figs. 3a, 3c and 3e) and methanolcyclohexane (Figs. 3b, 3d and 3f) systems. As discussed in section 2 and according to Fig. 1, the introduction of the "association" term in the EoS excess Gibbs energy of the NRTL-PRA equation enables a satisfactory prediction of both LLE and VLE, for both components ${ }^{(2)}$ (Figs. 3a-3d); on the contrary, the group contribution developed with the NRTL-PR model favors the representation of $V L E$, for both systems (Figs.3c and 3d), leading thus to overestimated critical mixing temperatures, with a rather unacceptable immiscibility domain for hexane (Fig. 3a).

For excess enthalpies, even if the NRTL-PRA EoS overestimates the prediction of $\mathrm{h}^{\mathrm{E}}$ for hexane (Fig. 3e), results are quite satisfactory for cyclohexane (Fig. 3f); it is not the case with the NRTL-PR equation, which mainly leads to $\mathrm{h}^{\mathrm{E}}$ predictions in the two-phase domain with, in addition, rather too high values of $h^{\mathrm{E}}$ for cyclohexane (Fig. 3f). Consequently, the "assumed $\mathrm{h}^{\mathrm{E}}$ equivalent predictions" of both models (Table 4) are mainly due to the estimated deviations in presence of large immiscibility domains.

In conclusion, the NRTL-PR modeling should be avoided for this kind of mixtures, and it is obviously no more considered for the comparison of NRTL-PRA EoS with other literature equations.

- Mixtures of methanol with aromatics, light gases and associating compounds: VLE and $h^{E}$ data $($ Table $4 b)$. Contrary to the previous case, all deviations on pressure and enthalpies are significant. We observe that the two modelings are quite similar and satisfactory; this conclusion could be expected, since these mixtures are close to those already described in the original paper [10] concerning the modeling of VLE and $\mathrm{h}^{\mathrm{E}}$ for water, or ethylene glycol, with hydrocarbons.

We would also point out the main difference between the two approaches. Even if no demixings are observed for systems containing methanol with aromatics or light gases, the NRTL-PRA EoS always assumes a dissociation of methanol during mixings; thanks to the use of decreasing values of the structural parameters (Eq. (14) and Table 2) involved in the "dissociation process", the equation is able to provide "slightly better" predictions for this kind of mixtures.

\section{2- Prediction of LLE, VLE and $h^{E}$ from NRTL-PRA and VTPR EoS}

This section compares two very close cubic EoS : both are based on the same " $E o S / g$ " formalism, using the same Peng-Robinson EoS [13], but with two different versions of the "two fluid theory" 
[27] for the EoS excess Gibbs energy, $g_{E o S}^{E}$. The NRTL-PRA EoS is based on the generalized NRTL Gibbs energy [12], derived from the original NRTL model [28], while the VTPR EoS [1] considers the UNIFAC model [29]. Moreover, both equations take account of the volume-translation [30] for the estimation of volumetric properties.

Due to their simplicity, cubic EoS can easily be used for the modeling of phase equilibria in multicomponent mixtures, as those considered in petroleum or pharmaceutical industry, as well as for fluid mechanics engineering. Consequently, the examination of the main strengths and weaknesses of each equation for the modeling of methanol with hydrocarbons, light gases and associating compounds is of great interest.

Besides, thanks to this "simplicity", it was also possible [10] to introduce the VTPR EoS in our general cubic algorithm in order to predict "all figures" of interest for the comparison of the two models (except for the systems methanol-cycloalkane, for which, according to us, no VTPR group contribution parameter was published in literature).

- Methanol with hydrocarbons leading to immiscible mixtures: LLE, VLE and $h^{E}$ data. This section concerns the modeling of mixtures methanol-paraffins and cycloalkanes reported in Table 4a. Due to the lack of VTPR parameters for cycloalkanes, the comparison is reduced to mixtures with paraffins in Fig. 4.

However, since the purpose of this work is to verify the behavior of the NRTL-PRA EoS, including for methanol-cycloalkane mixtures, it is worth taking also account of results presented in Table 4a, for all paraffins and cycloalkanes, and in Fig. 3 for hexane and cyclohexane; these results reveal a "rather similar" behavior of methanol with both hydrocarbons and for the various properties studied :

- a very satisfactory prediction of LLE is observed with the NRTL-PRA EoS: for paraffins, in Figs.4a and $4 \mathrm{~b}$ and Fig. $3 \mathrm{a}$, as well as for cyclohexane in Fig. $3 \mathrm{~b}$.

On the contrary, the VTPR equation (Figs. $4 \mathrm{a}$ and $4 \mathrm{~b}$ ) provides rather "poor" predictions of LLE, with an overestimation of the liquid-liquid domain, about 30 to $40 \mathrm{~K}$ for almost all paraffins. This behavior is consistent with the one observed in paragraph 3.1 with the NRTL-PR equation (Figs. 3a and 3b), which is rather similar to the VTPR EoS; but, in the case of VTPR, the overestimation of all critical demixing temperatures is "much more reasonable".

- Besides, for the prediction of VLE and $\mathrm{h}^{\mathrm{E}}$, already discussed in section 3.1 (Figs. 3.c and 3e, for methanol-hexane, and Figs. 3d and 3f for methanol-cyclohexane), the comparison with VTPR shows that: the NRTL-PRA EoS usually predicts pressures of the isothermal VLE "slightly" lower than those obtained with the VTPR equation (except for the system methanol-heptane, in Fig. 4c). The NRTL-PRA predictions of $\mathrm{h}^{\mathrm{E}}$, in Figs. $4 \mathrm{e}$ and $4 \mathrm{f}$, remain "reasonably higher" than those of the VTPR equation (except for butane, in Fig. 4e, with improved estimations).

- Methanol with compounds leading to totally miscible mixtures: VLE and $h^{E}$ data. As reported in Table $4 \mathrm{~b}$, the modeling concerns mixtures of methanol with aromatics, light gases and associating components; results are presented respectively in Figs. 5 to 7. They lead to the following conclusions:

- For aromatics, VLE and $\mathrm{h}^{\mathrm{E}}$ predictions obtained with the NRTL-PRA equation are very satisfactory and usually "better" than those obtained with the VTPR EoS (for both VLE, in Figs. 5a 
and $5 \mathrm{~b}$, and $\mathrm{h}^{\mathrm{E}}$, in Figs. $5 \mathrm{c}$ and $5 \mathrm{~d}$ ). As already mentioned in paragraph 3.1 for the comparison with the NRTL-PR equation, this improvement is mainly due to the fact that the NRTL-PRA EoS always assumes a dissociation of methanol, but, in this case, with "moderate" values of the structural parameters.

- Results for light gases are presented in Figs 6a-6c, for VLE with methane, $\mathrm{CO}_{2}$ and $\mathrm{H}_{2} \mathrm{~S}$, and in Fig. $6 \mathrm{~d}$, for $\mathrm{h}^{\mathrm{E}}$ with $\mathrm{CO}_{2}$. The NRTL-PRA EoS and, to some extent, the VTPR equation, provide an excellent modeling of all properties; nevertheless, as for aromatics, and for the same reasons, NRTLPRA predictions are always "slightly better".

- Finally, predictions of methanol-associating compounds systems are presented in Figs. 7a and 7b, for water, and in Figs. 7c and 7d, for ethylene glycol. The modeling of methanol-water with the NRTL-PRA EoS is very satisfactory, and much more better than with VTPR; in particular, the NRTL-PRA equation provides an excellent prediction of $\mathrm{h}^{\mathrm{E}}$ under high pressures (Fig. 7b). Concerning ethylene glycol, we only present results from the NRTL-PRA EoS, since we have no safe information about the corresponding VTPR group contributions; the system methanol-ethylene glycol is quite simple and the NRTL-PRA equation easily leads to perfect predictions.

In conclusion, the previous analysis has shown that: contrary to the VTPR equation, the NRTLPRA EoS provides quite satisfactory predictions of LLE, for a wide range of hydrocarbon sizes; for VLE and $\mathrm{h}^{\mathrm{E}}$, both models lead to rather comparable results, for hydrocarbons, and similar predictions for aromatics, light gases and associations compounds.

\section{3- Prediction of LLE and VLE from NRTL-PRA and SAFT type EoS.}

SAFT type equations [2-7], deriving from the original SAFT EoS [31], are well known for their strong theoretical bases, allowing to describe numerous properties and compounds of interest for petroleum, chemical or pharmaceutical industries. The challenge of this section is to compare predictions obtained with the "simple cubic" NRTL-PRA EoS to those of the "more theoretical" SAFT equations; among them, we have considered two predictive equations: the PC-SAFT [2-5] and the SAFT- $\gamma$-Mie [7] EoS.

It can be noted, in Figs. 8 and 9, that the comparison is restricted to a very small number of mixtures. Indeed, due to the complexity of these equations, only figures published in literature were considered for comparison with the NRTL-PRA equation; moreover, very few results concerning mixtures of methanol with hydrocarbons are published in literature.

- Comparison with PC-SAFT EoS. Literature data are reported in Fig. 8; according to our classification (Table 4), they concern mixtures of methanol with paraffins, namely LLE, for heptane and undecane, and VLE for propane, as well as light gases, by means of VLE for $\mathrm{CO}_{2}$. The analysis of Fig. 8 reveals that:

- for paraffins, predictions of LLE reported in Figs. 8a and 8b, for heptane and undecane, are "rather" satisfactory with the NRTL-PRA equation compared to the PC-SAFT one; for VLE with propane (Fig. 8c), the cubic EoS shows a tendency to predict "lower" pressures in isothermal conditions. 
- For light gases, represented only by the VLE of $\mathrm{CO}_{2}$ (Fig. 8d), the NRTL-PRA equation provides the best results.

- Comparison with the SAFT- $\gamma$-Mie EoS. Phase equilibria presented in Fig. 9 correspond to mixtures of methanol with: paraffins, with LLE and VLE for hexane and VLE for butane, light gases, with LLE and VLE for ethane, and associating compounds, with VLE for water. The analysis of Fig. 9 reveals that:

- for paraffins, the predictions of LLE and VLE obtained with the two models in Fig. 9a are very close, with, however, always the same tendency of the NRTL-PRA equation to slightly underestimate the pressure of isothermal VLE (Fig. 9b).

- For light gases (Fig. 9c for ethane), the two models provide very satisfactory predictions, with a "slightly" better calculation of the liquid phase rich in ethane by the NRTL-PRA EoS; it can be noted that the same tendency was previously observed for VLE of methanol- $\mathrm{CO}_{2}$ for the comparison with the PC-SAFT equation.

- For associating compounds (Fig. 9d for water), the two models provide exactly the same excellent predictions.

Finally, even if the number of mixtures considered is too restricted to enable general conclusions, the above results show that: first, the NRTL-PRA cubic EoS provides predictions "rather similar" to those of both SAFT versions; second, the proposed EoS is the only one that gives "reasonable" predictions of excess enthalpies.

\section{Conclusion}

The cubic NRTL-PR EoS [9,10], based on the generalized NRTL Gibbs energy [12] associated with the Peng-Robinson equation of state, was previously proposed for the prediction of either VLE and $h^{E}$ of hydrocarbon mixtures, or VLE or LLE of systems including hydrocarbons with associating compounds (water and ethylene glycol). The main success of this modeling, using only asymmetrical group interaction parameters between associating compounds and hydrocarbons, is due to the fact that experimental data concerned only one kind of phase equilibria (VLE or LLE).

For mixtures containing methanol with hydrocarbons, namely paraffins and cycloalkanes, the modeling, which requires the simultaneous prediction of LLE, VLE, and $\mathrm{h}^{\mathrm{E}}$, is much more complex. For this purpose, an additional term was introduced in the original EoS excess Gibbs energy of the Peng-Robinson equation to account for the self-association of methanol, leading thus to the NRTLPRA EoS. The strengths of the proposed equation are the following:

- first, the new EoS remains a simple cubic equation which can be easily used, with reasonable computing times, for the modeling of phase equilibria in multicomponent mixtures, as those considered in petroleum or pharmaceutical industry, as well as for fluid mechanics engineering;

- second, the equation does not require any additional parameter for the associating compound, except the knowledge of its enthalpy, $\Delta H_{\left(T_{0}\right)}^{0}$, and entropy, $\Delta S_{\left(T_{0}\right)}^{0}$, of association at a reference temperature $T_{0}$; 
- third, the NRTL-PRA EoS simply reduces to the original NRTL-PR EOS for the modeling of VLE or LLE in mixtures containing hydrocarbons and associating compounds (water and ethylene glycol being considered in this case as "non associated").

The new equation was applied to the prediction of phase equilibria and excess enthalpies of mixtures containing methanol with paraffins, cycloalkanes, aromatics, light gases, water and ethylene glycol. A first attempt to correlate these data by means of a group contribution specially developed with the original NRTL-PR EoS (Table 4 and Fig. 3) evidenced the need of taking account of the dissociation of methanol during mixings. The NRTL-PRA EoS was then compared with literature predictive equations: the cubic VTPR EoS [1] and two SAFT type equations, PC-SAFT [2-5] and SAFT- $\gamma$-Mie [7] (even if in this case, the restricted number of systems considered does not enable "general" conclusions).

Results of the various comparisons showed that:

- for mixtures with paraffins and cycloalkanes, the NRTL-PRA equation leads, for a wide range of hydrocarbon sizes, to satisfactory predictions of LLE, similar to those of SAFT type EoS; it was also verified that the VTPR equation provides "rather poor" predictions of LLE. Concerning VLE predictions, the NRTL-PRA EoS may lead to isothermal VLE curves "slightly lower" than those obtained with the two other models. Predictions of $\mathrm{h}^{\mathrm{E}}$ data are interesting, since they remain "reasonably higher" than those of the VTPR model; it is worth recalling that SAFT EoS provide no information about the representation of excess enthalpies.

- For all other mixtures containing aromatics, light gases and other associating components, for which most of literature EoS only consider VLE data, the NRTL-PRA EoS (as the VTPR equation) provides very satisfactory and precise predictions of both VLE and $\mathrm{h}^{\mathrm{E}}$ data, especially for mixtures with light gases and associating compounds.

To summarize: the proposed NRTL-PRA EoS appears to be suitable for the modeling of any mixtures involving hydrocarbons with associating components (like methanol, ethanol...). With respect to other predictive EoS, the strength of the proposed equation is twofold: first, it remains a simple cubic EoS, as VTPR, but allowing a satisfactory prediction of LLE; second, it provides LLE and VLE predictions comparable to those of SAFT EoS, but allowing rather meaningful predictions of enthalpies.

\section{Acknowledgements}

The authors would like to acknowledge financial support from TOTAL S.A. We thank Laurent Avaullée and François Montel for useful discussions and valuable input.

\section{List of symbols}

$a=$ attractive term

$b=$ covolume

$g=$ molar Gibbs free energy

$n=$ mole number

$P=$ pressure 
$q=$ surface area factor

$Q_{k}=$ UNIFAC surface parameter subgroups

$r=$ volume area factor

$R=$ ideal gas constant

$R_{k}=$ UNIFAC volume parameter subgroups

$S_{k}=$ stereochemistry parameter subgroups

$T=$ temperature

$v=$ molar volume

$Z=$ compressibility factor

$x=$ mole fraction

\section{Greek letters}

$\alpha=$ alpha function

$\Gamma_{j i}=$ interaction parameter between molecules $j$ and $i$

$\Gamma_{L K}{ }^{(0)}, \Gamma_{L K}{ }^{(1)}, \Gamma_{L K}{ }^{(2)}=$ interaction parameters between main groups $K$ and $L$

$\omega=$ acentric factor

$\theta_{i K}=$ probability that a contact from molecule $i$ involves a main group $K$

$v_{i K}=$ number of main group $K$ in a molecule $i$

\section{Subscript}

asso $=$ association property

$c o m b=$ combinatorial property

diss $=$ dissociation property

$i=$ pure component property

res $=$ residual property

Superscript

$E=$ excess property at constant pressure

\section{APPENDIX A: Calculation of polymer mole fractions}

The calculation of mixture properties requires, besides the mole fraction $x_{i}$, the knowledge of the global mole fractions of polymers, $X_{i}$ and $X_{i}^{\left(x_{i}=1\right)}$, respectively in the mixture and in the pure component $i$ :

$$
X_{i}=\sum_{k} X_{i k} \quad, \quad x_{i}=\sum_{k} k X_{i k} \quad \text { with : } \quad X_{i k}=\left(K_{i} X_{i 1}\right) / X_{i(k-1)}
$$

and:

$$
1=\sum_{k} k X_{i k}^{\left(x_{i}=1\right)}, \quad X_{i}^{\left(x_{i}=1\right)}=\sum_{k} X_{i k}^{\left(x_{i}=1\right)}
$$


where, $K_{i}$ represents, according to Eq. (12) the "pseudo equilibrium" constant of the polymerization reaction (Eq. (7)).

- For a series of polymers $k$, the global mole fraction of polymers $X_{i}$ (Eq. (A-1)) is expressed as :

$$
X_{i}=\sum_{k=1}^{p} X_{i k}=X_{i 1}+\left(K_{i} X_{i 1}\right) \sum_{k=2}^{p} k X_{i(k-1)}=X_{i 1}+\left(K_{i} X_{i 1}\right)\left[X_{i}-X_{i p}\right]
$$

Assuming that the mole fraction, $X_{i p}$, of the highest polymer $p$ is negligible, the above equation becomes:

$$
X_{i} \approx X_{i 1}\left(1+K_{i} X_{i}\right)
$$

so that, Eq. (A-3) reduces to:

$$
X_{i}=X_{i 1} /\left(1-K_{i} X_{i 1}\right)
$$

- The mole fraction $x_{i}$ (Eq. A-1) can also be written as:

$$
\begin{aligned}
x_{i}=\sum_{k=1}^{p} k X_{i k} & =X_{i 1}+\left(K_{i} X_{i 1}\right)\left[\sum_{k=2}^{p}(k-1) X_{i(k-1)}+\sum_{k=2}^{p} X_{i(k-1)}\right] \\
& =X_{i 1}+\left(K_{i} X_{i 1}\right)\left[\left(x_{i}-p X_{i p}\right)+\left(X_{i}-X_{i p}\right)\right]
\end{aligned}
$$

Assuming also that $X_{i p}$ is negligible, the previous relation (Eq. (A-6)) becomes:

$$
x_{i}=X_{i 1}\left(1+K_{i} x_{i}\right)+\left(K_{i} X_{i 1}\right) X_{i}
$$

so that the mole fraction of polymers, $X_{i}$, given by Eq. (A-5) leads to a second degree equation with respect to the variable $X_{i 1}$, the solution of which is:

$$
X_{i 1}=\left[\left(1+2 K_{i} x_{i}\right)-\sqrt{1+4 K_{i} x_{i}}\right] /\left[2 K_{i}^{2} x_{i}\right]
$$

- It should also be noted that, in the case where mixture components $m$ are "highly polar" $\left(P_{i}-P_{m}=0\right)$ or have "very small size" $\left(\sigma_{m, i}=r_{m, i} \sim \mathcal{E}\right)$, Eq. (13) shows that: $\operatorname{gam}_{i} \sim x_{i}$, so that the "pseudo equilibrium" constant $K_{i}$ (Eq. (12)) can be expressed by : $K_{i} x_{i} \sim \exp \left(-\Delta G_{i}^{0} / R T\right)$, it means as a simple term independent of mole fractions $x_{i}$.

Consequently, Eq. (A-8) which can be rewritten as:

$$
X_{i 1} / x_{i}=\left[\left(1+2\left(K_{i} x_{i}\right)\right)-\sqrt{1+4\left(K_{i} x_{i}\right)}\right] /\left[2\left(K_{i} x_{i}\right)^{2}\right]
$$

shows that $X_{i 1} / x_{i}$ is also independent of mole fractions $x_{i}$. Finally, the auxiliary variable $X_{i} / x_{i}$ is expressed, from Eq. (A-5), as: 


$$
X_{i} / x_{i}=\left(X_{i 1} / x_{i}\right) /\left[1-\left(K_{i} x_{i}\right)\left(X_{i 1} / x_{i}\right)\right]
$$

It means as a constant with respect to the mixture composition. The dissociation excess Gibbs energy (Eq. (10)) becomes therefore : $g_{\text {diss }}^{E}=\sum_{i=i(\text { asso })} x_{i}\left(X_{i}^{\left(x_{i}=1\right)}-X_{i} / x_{i}\right) E_{i(\text { asso })}^{0} \sim 0$.

The main consequence of these "limiting cases" is therefore that such mixings lead to totally miscible mixtures.

\section{References}

J. Ahlers, J. Gmehling, Ind. Eng. Chem. Res. 41 (2002b) 5890-5899.

P. C. V. Tybjerg, G. M. Kontogeorgis, M. L. Michelsen, E. H. Stenby, Fluid Phase Equilib. 288 (2010) 128-138.

J. Gross, G. Sadowski, Ind. Eng. Chem. Res. 41 (2002) 5510-5515.

M. Yarrison, W.G. Chapman, Fluid Phase Equilib. 226 (2004) 195-205.

L.A. Roman-Ramirez, F. Garcia-Sanchez, C.H. Ortiz-Estrada, D.N. Justo-Garcial, Ind. Eng. Chem. Res. 49 (2010) 12276-12283.

M. Mourah, D. NguyenHuynh, J. P. Pasarello, J. C. de Hemptinne, P. Tobaly, Fluid Phase Equilib. 298 (2010) 154-168.

V. Papaioannou, F. Calado, T. Lafitte, S. Dufal, M. Sadeqzadeh, G. Jackson, C.S. Adjiman, A. Galindo, Fluid Phase Equilib. 416 (2016) 104-119.

H.P. Gros, S. Bottini, E.A. Brignole, Fluid Phase Equilib. 116 (1996) 537-.

E. Neau, J. Escandell, C. Nicolas, Ind. Eng. Chem. Res. 49 (2010) 7589-7596.

J. Escandell, E. Neau, C. Nicolas, Fluid Phase Equilib. 301 (2011) 80-97.

J. Vidal, Chem.Eng.Sci., 33 (1978) 787-791..

E. Neau, J. Escandell, C. Nicolas, Ind. Eng. Chem. Res. 49 (2010) 7580-7588.

D.Y. Peng, D.B. Robinson, Ind. Chem. Fundam. 15 (1976) 59-64.

E. Neau, J. Escandell, I. Raspo, Chem. Eng. Sci. 66 (2011) 4148-4156.

E. Neau, M. Rogalski, P. Alessi, M. Fermeglia, Fluid Phase Equilib. 56 (1990) 189202.

Feeney J., Walker S.M., J. Chem. Soc. A (1966) 1148-1152.

Schuman E.M., Dwyer D.W., Doetschman D.C., J. Phys. Chem. 94 (1990) 7308- 7312.

Wallen S.L., Palmer B.J., Garrett B.C., Yonker C.R., J. Phys. Chem. 100 (1996) 39593964.

Hoffmann M.M., Conradi M.S., J. Phys. Chem. B 102 (1998) 263-271.

Pagliai M., Cardini G., Righini R., Schettino V., J. Chem. Phys. 119 (13) (2003) 66556662.

Park B.H., Kang J.W.,Yoo K.-P., Lee C.S., Fluid Phase Equilib. 183-184 (2001) 111119.

H.K Hansen, P. Rasmussen, A. Fredenslund, M. Schiller, J. Gmehling, Ind. Eng. Chem. Res.,30 (1991) 2352-2355. 
T. Holderbaum, J. Gmehling, Fluid Phase Equilib. 70 (1991) 251-265.

E. Neau, I. Raspo, J. Escandell, C. Nicolas, O. Hernández-Garduza, Fluid Phase Equilib. 276 (2009) 156-164.

G. Soave, Chem. Eng. Sci. 27 (1972) 1197-1340.

D.B. Robinson, D.Y. Peng, Gas Processors Association Research Report, EdmontonAlberta, 1978.

Guggenheim E.A., "Mixtures. The theory of equilibrium properties for some simple classes of mixtures, solutions and alloys”, Clarendon Press, Oxford, 1952

H. Renon, J.M. Prausnitz, AIChEJ 14 (1968) 135-144.

G. Maurer, J.M. Prausnitz, Fluid Phase Equilib. 2 (1978) 91-99

A.Péneloux, E.Rauzy, R.Freze, Fluid Phase Equilib. 8 (1982) 7-23

W.G. Chapman, K.E. Gubbins, G. Jackson, G.Radoz, Fluid Phase Equilib. 52 (1989) 31-38.

G. Hradetzky, D.A. Lempe, Fluid Phase Equilib. 69 (1991) 285-301.

H. Matsuda, K. Kurihara, K. Ochi, K. Kojima, Fluid Phase Equilib. 203 (2002) 269284.

B. Orge, M. Iglesias, A. Rodrigez, J.M. Canosa, J. Tojo, Fluid Phase Equilib. 133 (1997) 213-227.

H. Katayama, Fluid Phase Equilib. 164 (1999) 83-95

R.W. Kiser, G.D. Johnson, M.D. Shetlar, J. Chem. Eng. Data 6 (1961) 338-341.

H. Matsuda, K. Ochi, K. Kojima, J. Chem. Eng. Data 48 (2003) 184-189.

H. Wolff, H.E. Hoeppel, Ber. Bunsen-Ges. Phys. Chem. 72 (1968) 710-721.

A. Zawisza, J. Chem. Thermodyn. 17 (1985) 941-947.

P. Oracz, M. Goral, G. Wilczek-Vera, S. Warycha, Fluid Phase Equilib. 126 (1996) 7192.

A.N. Marinichev, M.P. Susarev, Zh. Prikl. Khim. 38 (1965) 1619

S. Madhavan, P.S. Murti, Chem. Eng. Sci. 21 (1966) 465-468.

A.G. Morachevskii, E.G Komarova., Vestn. Leningr. Univ. Fiz. Khim. 12 (1957) 118.

K. Strubl, Svoboda V., R. Holub, J. Pick, Collect. Czech. Chem. Commun. 35 (1970) 3004.

C.G. Savini, D.R. Winterhalter, H.C. van Ness, J. Chem. Eng. Data 10 (1965) 171-172.

K. Kurihara, T. Iguchi, K. Ochi, K. Kojima, Fluid Phase Equilib. 144 (1998) 169-180.

A.N. Campbell, E.M. Kartzmark, Can. J. Chem. 48 (1970) 904.

U. Haarhaus, G.M. Schneider, J. Chem. Thermodyn. 20 (1988) 1121-1129.

K. Kurihara, T. Midorikawa, T. Hashimoto, K. Kojima, K. Ochi, J. Chem. Eng Jap. 35 (2002) 360-364.

J.B. Ott, I.F. Hölscher, G.M. Schneider, J. Chem. Thermodyn. 18 (1986) 815-826.

K. Kammerer, G. Oswald, E. Rezanowa, D. Silkenbäumer, R.N. Lichtenthaler, Fluid Phase Equilib. 167 (2000) 223-241.

J.J. Segovia, M.C. Martin, C.R. Chamorro, M.A.V illamanan, J. Chem. Thermodyn. 31 (1999) 1231-1246.

J.D. Lee, T.J. Lee, S.J. Park, J. Korean Ind. Eng. Chem., 5 (1994) 706-713. 
A.D. Leu, D.B. Robinson, J. Chem. Eng. Data 37 (1992) 10-13.

J.T. Sipowska, J.B. Ott, A.T. Woolley, R.M. Izatt., J. Chem. Thermodyn. 24 (1992) 1087-1093.

S.C. Lee, J. Phys. Chem. 35 (1931) 3558-3582.

K.L. Butcher, M.S. Medani, J. Appl. Chem. 18 (1968) 100-107.

J.H. Oh, K.J. Han, D.B. Won, S.J. Park, Fluid Phase Equilib. 209 (2003) 215-228.

P. Oracz, G. Kolasinska, Fluid Phase Equilib. 35 (1987) 253-278.

Zhu Ziqiang, Huagong Xuebao (J. Chem. Ind. Eng.), 1 (1984) 51.

A.G. Williamson, R.L. Scott, J. Phys. Chem. 64 (1960) 440-442.

L.S. Mason, E.R. Washburn, J. Phys. Chem. 40 (1936) 481-491.

C.C. Tsao, J.M. Smith, Chem. Eng. Prog. Symp. Ser. 49 (1953) 107-117.

J.H. Hong, P.V. Malone, M.D. Jett, R. Kobayashi, Fluid Phase Equilib. 38 (1987) 8396.

E. Brunner, W. Hueltenschmidt, G. Schichthaerle, J. Chem. thermodyn. 19 (1987) 273291.

A.E. Messner, D.M. Rosie, P.A. Argabright, Anal. chem. 31 (1959) 230-233.

J.H. Hong, R. Kobayashi, Fluid Phase Equilib. 41 (1988) 269-276.

I.R. Krichevskii, E.S. Lebedeva, Zh. Fiz. Khim. 21 (1947) 715-718.

F. Schroedter, W.M .Melzer, H. Knapp, Gas Sep. Purif. 5 (1991) 161-172.

W. Weber, S. Zeck, H. Knapp, Fluid Phase Equilib. 18 (1984) 253-278.

C.J. Chang, C.Y. Day, C.M. Ko, K.L. Chiu, Fluid Phase Equilib. 131 (1997) 243-258.

C.J. Chang, K.L. Chiu,, C.Y. Day, J. Supercrit. Fluid 12 (1998) 223-237.

M.M.Elbaccouch, M.B. Raymond, J.R. Elliott, J. Chem. Eng. Data 45 (2000) 280-287.

T. Laursen, P. Rasmussen, S.I. Andersen, J. Chem. Eng. Data 47 (2002) 198-202.

S.N. Joung, C.W. You, H.Y. Shin, Fluid Phase Equilib. 185 (2001) 219-230.

A.D. Leu, S.Y.K. Chung, D.B. Robinson, J. Chem. Thermodyn. 23 (1991) 979-985.

A.D. Leu, J.J. Carroll, D.B. Robinson, Fluid Phase Equilib. 72 (1992) 163-172.

J.J. Christensen, D.R. Cordray, J.L. R.M. Oscarson, R.M. Izatt, J. Chem. Thermodyn. 20 (1988) 867-875.

K. Kurihara, T. Minoura, K. Takeda, K. Kojima., J. Chem. Eng. Data 40 (1995) 679684.

J.M. Simonson, D.J. Bradley, R.H. Busey, J. Chem. Thermodyn. 19(1987) 479-492.

I.S. Sedletskaya, V.B. Kogan, Zh. Prikl. Khim. 42 (1969) 2551.

H.J. Bittrich, R. Eckert, Z. Phys. chem. 175 (1992) 217-234.

C. Kracht, P. Ulbig, S. Schulz, Thermochimica Acta 337 (1999) 209-217. 


\section{LIST OF TABLES}

Table 1. The NRTL-PRA EoS.

Table 2. NRTL-PRA group contributions: volume parameter $R_{k}$, surface area parameter $Q_{k}$ and stereochemistry parameter $S_{k}$.

Table 3a. Values (in J/mol) of the NRTL-PRA group interaction parameters $\Gamma_{L K}^{(0)}$

Table 3b. Values (in J/mol) of the NRTL-PRA group interaction parameters $\Gamma_{L K}^{(1)}$

Table 3c. Values (in J/mol) of the NRTL-PRA group interaction parameters $\Gamma_{L K}^{(2)}$

Table 4a. Modeling of VLE, $\mathrm{h}^{\mathrm{E}}$ and LLE for mixtures containing methanol $\left(\right.$ component ${ }^{(1)}$ ) and paraffins or cycloalkanes. Comparison of results obtained with: (I) «NRTL-PRA» and (II) « NRTL-PR» EoS. Representation of experimental data : number of data points $\left(N_{V L E}, N_{h E,}, N_{x 1} N_{x 2}\right)$, maximum temperature $T_{\max }(\mathrm{K})$ and pressure $P_{\max }(\mathrm{MPa})$, deviations $(\triangle P / P \%)$ on pressure, $\left(\Delta h^{E} / h^{E} \%\right)$ on excess enthalpies and $\left(\Delta x_{1} / x_{1} \%, \Delta x_{2} / x_{2} \%\right)$ on the mole fractions respectively in the « hydrocarbon » and « methanol $»$ rich phases.

Table 4b. Modeling of VLE and $\mathrm{h}^{\mathrm{E}}$ for mixtures containing methanol (component ${ }^{(1)}$ ) and aromatics, light gases and associating components. Comparison of results obtained with : (I) «NRTL-PRA » and $(I I)$ «RTL-PR» EoS . Representation of experimental data : number of data points $\left(N_{V L E}, N_{h E}\right)$, maximum temperature $T_{\max }(\mathrm{K})$, deviations $(\Delta P / P \%)$ on pressure and $\left(\Delta h^{E} / h^{E} \%\right)$ on excess enthalpies.

\section{FIGURES CAPTIONS}

Figure 1. Methanol $^{(1)}-$ hexane ${ }^{(2)}$ system. Excess Gibbs energy $g_{E o S}^{E} / R T$ (see Table 1) calculated for $x=0.5$ as a function of temperature, respectively for: NRTL-PR EOS ( - - ), with: $g_{E o S}^{E}=g_{\text {res }}^{E}$ and NRTL-PRA $\operatorname{EoS}(-)$, with: $g_{E o S}^{E}=g_{\text {diss }}^{E}+g_{\text {res }}^{E}$.

Figure 2. Illustration of the free energy of mixing $g^{M}$ for a mixture of non-associating compounds and for a mixture containing one associating compound.

Figure 3. Methanol $^{(1)}$ with paraffins ${ }^{(2)}$ and cycloalkanes ${ }^{(2)}$. Simultaneous prediction of LLE, VLE and $\mathrm{h}^{\mathrm{E}}$ with the NRTL-PRA (-) and the NRTL-PR (- - ) EoS. (a) Hexane ${ }^{(2)}$ : LLE under P = 0.101 MPa [32-34]. (b) Cyclohexane ${ }^{(2)}$ : LLE under $\mathrm{P}=0.101 \mathrm{MPa}$ [35-37]. (c) Hexane ${ }^{(2)}$ : VLE at $(\square) \mathrm{T}=343 \mathrm{~K}$ [38] and $(\Delta) \mathrm{T}=398 \mathrm{~K}$ [39]. (d) Cyclohexane ${ }^{(2)}$ : VLE at $(\square) \mathrm{T}=293 \mathrm{~K}$ [40] and $(\Delta) \mathrm{T}=328 \mathrm{~K}$ [4144]. (e) Hexane ${ }^{(2)}: h^{E}$ under $\mathrm{P}=0.2 \mathrm{MPa}$ and at $(\square) \mathrm{T}=298 \mathrm{~K}[45],(\diamond) \mathrm{T}=313 \mathrm{~K}[45]$ and $(\Delta) \mathrm{T}=$ $323 \mathrm{~K}[45] .(f)$ Cyclohexane ${ }^{(2)}: \mathrm{h}^{\mathrm{E}}$ under $\mathrm{P}=0.2 \mathrm{MPa}$ and at $(\square) \mathrm{T}=288 \mathrm{~K}[46]$ and $(\Delta) \mathrm{T}=323 \mathrm{~K}$ [47]; straight lines represent the two phase regions. 
Figure 4. Methanol $^{(1)}$-paraffins ${ }^{(2)}$ systems. Prediction of LLE, VLE and $\mathrm{h}^{\mathrm{E}}$ with the NRTL-PRA ( - ) and the VTPR (- $)$ equations. (a) Butane ${ }^{(2)}$ : LLE at ( $\left.\square\right) \mathrm{P}=5 \mathrm{MPa}[48]$. (b) Octane ${ }^{(2)}$ : LLE at ( $\square$ ) P $=1 \mathrm{MPa}[49,50]]$. (c) Heptane ${ }^{(2)}$ : VLE at $(\square) \mathrm{T}=313 \mathrm{~K}$ [51,52] and $(\diamond) \mathrm{T}=338 \mathrm{~K}$ [53]. (d) 2Methylpropane $^{(2)}$ : VLE at $(\square) \mathrm{T}=373 \mathrm{~K}[54]$ and $(\Delta) \mathrm{T}=423 \mathrm{~K}[54]$. (e) Butane ${ }^{(2)}: \mathrm{h}^{\mathrm{E}}$ under $\mathrm{P}=5$ $\mathrm{MPa}$ and at $(\square) \mathrm{T}=298 \mathrm{~K}[55],(\diamond) \mathrm{T}=323 \mathrm{~K}[55]$ and $(\Delta) \mathrm{T}=348 \mathrm{~K}[55] .(f)$ Heptane $^{(2)}: \mathrm{h}^{\mathrm{E}}$ under $\mathrm{P}$ $=0.2 \mathrm{MPa}$ and at $(\square) \mathrm{T}=303 \mathrm{~K}[45],(\diamond) \mathrm{T}=318 \mathrm{~K}$ [45] and $(\Delta) \mathrm{T}=333 \mathrm{~K}$ [45]; straight lines represent the two phase regions.

Figure 5. Methanol ${ }^{(1)}$-aromatics ${ }^{(2)}$ systems. Prediction of VLE and $\mathrm{h}^{\mathrm{E}}$ with the NRTL-PRA $(\longrightarrow)$ and the VTPR (- -) equations. (a) Benzene ${ }^{(2)}$ : VLE at (口) $\mathrm{T}=313 \mathrm{~K}$ [56], (०) $\mathrm{T}=373 \mathrm{~K}$ [57] and $(\Delta) \mathrm{T}=$ $453 \mathrm{~K}$ [57]. (b) Toluene ${ }^{(2)}$ : VLE at (口) $\mathrm{T}=313 \mathrm{~K}[58,59]$. (c) Benzene ${ }^{(2)}: \mathrm{h}^{\mathrm{E}}$ under $\mathrm{P}=0.101 \mathrm{MPa}$ and at $(\square) \mathrm{T}=298 \mathrm{~K}[60]$ and $(\diamond) \mathrm{T}=318 \mathrm{~K}[61] .(d)$ Toluene $^{(2)}: \mathrm{h}^{\mathrm{E}}$ under $\mathrm{P}=0.101 \mathrm{MPa}$ and at $(\square) \mathrm{T}$ $=298 \mathrm{~K}[62,63]$ and $(\diamond) \mathrm{T}=308 \mathrm{~K}[62]$.

Figure 6. Methanol ${ }^{(1)}$-light gases ${ }^{(2)}$ systems. Prediction of VLE and $\mathrm{h}^{\mathrm{E}}$ with the NRTL-PRA ( - ) and the VTPR ( $-\rightarrow$ equations. (a) Methane ${ }^{(2)}$ : VLE at $(\square) \mathrm{T}=220 \mathrm{~K}[64],(\diamond) \mathrm{T}=323 \mathrm{~K}[65]$ and $(\Delta)$ $\mathrm{T}=373 \mathrm{~K}$ [65]. (b) Carbon dioxide ${ }^{(2)}: \mathrm{VLE}$ at $(\square) \mathrm{T}=273 \mathrm{~K}$ [66-70], ( $\left.\diamond\right) \mathrm{T}=313 \mathrm{~K}$ [71-75] and $(\Delta)$ $\mathrm{T}=352 \mathrm{~K}$ [76]. (c) Hydrogen sulfide ${ }^{(2)}$ : VLE at $(\square) \mathrm{T}=298 \mathrm{~K}[77],(\bullet) \mathrm{T}=348 \mathrm{~K}$ [77] and $(\Delta) \mathrm{T}=$ $398 \mathrm{~K}$ [77]. (d) Carbon dioxide ${ }^{(2)}: \mathrm{h}^{\mathrm{E}}$ at $\mathrm{P}=12.5 \mathrm{MPa}$ at $(\square) \mathrm{T}=308 \mathrm{~K}$ [78], ( $\left.\diamond\right) \mathrm{T}=473 \mathrm{~K}[78]$ and $(\Delta) \mathrm{T}=573 \mathrm{~K}[78]$

Figure 7. Methanol ${ }^{(1)}$ - associating compounds ${ }^{(2)}$ systems. Prediction of VLE and $\mathrm{h}^{\mathrm{E}}$ with the NRTLPRA (-) and the VTPR (- - ) equations. (a) Water ${ }^{(2)}$ : VLE at ( $\left.\square\right) \mathrm{T}=328 \mathrm{~K}[79]$ and (०) $\mathrm{T}=333 \mathrm{~K}$ [79]. (b) Water ${ }^{(2)}: \mathrm{h}^{\mathrm{E}}$ under $\mathrm{P}=20 \mathrm{MPa}$ at $(\square) \mathrm{T}=298 \mathrm{~K}[80],(\diamond) \mathrm{T}=373 \mathrm{~K}[80]$ and $(\Delta) \mathrm{T}=523 \mathrm{~K}$ [80]. (c) Ethylene glycol ${ }^{(2)}$ : VLE at $(\square) \mathrm{T}=313 \mathrm{~K}$ [81] and $(\diamond) \mathrm{T}=333 \mathrm{~K}$ [82]. (d) Ethylene glycol ${ }^{(2)}$ : $\mathrm{h}^{\mathrm{E}}$ under $\mathrm{P}=0.1 \mathrm{MPa}$ at $(\square) \mathrm{T}=298 \mathrm{~K}[83]$ and $(\diamond) \mathrm{T}=308 \mathrm{~K}[83]$.

Figure 8. Methanol $^{(1)}$ with paraffins ${ }^{(2)}$ and light gases ${ }^{(2)}$. Prediction of LLE and VLE with NRTLPRA ( - - ) and PC-SAFT $(-)$ equations. (a) Heptane ${ }^{(2)}$ : LLE under P = $1 \mathrm{MPa}$ (SAFT curves from [4]). (b) Undecane ${ }^{(2)}$ : LLE under $\mathrm{P}=2 \mathrm{MPa}$ (SAFT curves from [6]). (c) Propane ${ }^{(2)}$ : VLE at (o) $\mathrm{T}=$ $313 \mathrm{~K}$ and $(\diamond) \mathrm{T}=343 \mathrm{~K}$ (SAFT curves from [4]). (d) Carbon dioxide ${ }^{(2)}$ : VLE at $\mathrm{T}=353 \mathrm{~K}$ (SAFT curves from [5]).

Figure 9. Methanol $^{(1)}$ with paraffins ${ }^{(2)}$, light gases ${ }^{(2)}$ and associating compounds ${ }^{(2)}$. Prediction of phase equilibria with the NRTL-PRA EoS (- *-) and the curves [7] from the SAFT- $\gamma$ Mie equation (一).

(a) Hexane ${ }^{(2)}$ : (口) LLE and (o) VLE under P = 0.101 MPa. (b) Butane ${ }^{(2)}$ : VLE at (o) $\mathrm{T}=323 \mathrm{~K}$ and

$(\square) \mathrm{T}=373 \mathrm{~K}$. (c) Ethane ${ }^{(2)}:(\Delta)$ VLE and $(\diamond)$ LLE at T = $298 \mathrm{~K} .(d)$ Water ${ }^{(2)}$ : VLE at $(\square) \mathrm{T}=298 \mathrm{~K}$,

$(\circ) \mathrm{T}=308 \mathrm{~K},(\Delta) \mathrm{T}=323 \mathrm{~K}$ and $(\diamond) \mathrm{T}=333 \mathrm{~K}$. 
Table 1. The NRTL-PRA EoS.

\section{(a) - General formulae}

$$
Z=\frac{P v}{R T}=\frac{1}{1-\eta}-\frac{\alpha}{1+2 \eta-\eta^{2}} \quad, \quad \eta=\frac{b}{v}
$$

With :

$$
\alpha=\sum_{i} x_{i} \frac{a_{i}}{b_{i} R T}-\frac{1}{0.53}\left[\frac{\boldsymbol{g}_{\text {EoS }}^{\boldsymbol{E}}}{R T}\right] \quad, \quad b=\sum_{i} x_{i} b_{i}
$$

and, in the case of associating components i(asso):

$$
g_{E o S}^{E}=g_{\text {diss }}^{E}+g_{\text {res }}^{E}
$$

$$
\left\{\begin{array}{c}
\boldsymbol{g}_{\text {diss }}^{\boldsymbol{E}}=\sum_{i=i(\text { asso })}\left(x_{i} X_{i}^{\left(x_{i}=1\right)}-X_{i}\right) E_{i(\text { asso })}^{0}, \quad E_{i(\text { asso })}^{0}=\Delta G_{i}^{0}-(2 / z) E_{i i} \quad(z=10) \\
X_{i}=X_{i 1} /\left(1-K_{i} X_{i 1}\right), \quad X_{i 1}=\left(1+2 K_{i} x_{i}-\sqrt{1+4 K_{i} x_{i}}\right) /\left[2 K_{i}^{2} x_{i}\right] \\
K_{i}=\exp \left(-\Delta G_{i}^{0} / R T\right) / g a m_{i} \quad, \quad \operatorname{gam}_{i}=x_{i}+\sum_{m \neq i(a s s o)} x_{m}\left(\sigma_{m, i} / \sigma_{i}\right) \\
\boldsymbol{g}_{\text {res }}^{\boldsymbol{E}}=\sum_{i} x_{i} q_{i} \frac{\sum_{j} x_{j} q_{j} G_{j i} \Gamma_{j i} x_{m} q_{m} G_{m i}}{m} \\
q_{i}=q_{i 1}-\left(1-X_{i} / x_{i}\right) / 2 / z \\
\Gamma_{j i}=E_{j i}-E_{i i}, G_{j i}=\exp \left(-\alpha_{0} \Gamma_{j i} / R T\right), \alpha_{0}=-1
\end{array}\right.
$$

(b) - Specific parameters for methanol (energies in $\mathrm{J} / \mathrm{mol}$ )

$$
\left\{\begin{array}{l}
\gamma_{i}=0.9 \quad, \quad m_{i}=0.6969 \quad \text { (parameters of the Soave function) } \\
r_{i}=2.1711, \quad q_{i}=2.0000 \text { (UNIFAC subgroup parameters) } \\
\Delta G_{i}^{0}=-10589.78-6410.23\left(T_{0} / T-1\right) \quad, \quad T_{0}=298.15 \mathrm{~K} \\
E_{i(\text { asso })}^{0}=-9980.62-6833.96\left(T_{0} / T-1\right)
\end{array}\right.
$$


Table 2. NRTL-PRA group contributions: volume parameter $R_{k}$, surface area parameter $Q_{k}$ and stereochemistry parameter $S_{k}$.

\begin{tabular}{|c|c|c|c|c|c|}
\hline Main groups $\mathrm{K}$ & Subgroups k & $\mathrm{R}_{\mathrm{k}}$ & $\mathrm{Q}_{\mathrm{k}}$ & $S_{k}$ & Ref. $\left(\mathrm{R}_{\mathrm{k}}, \mathrm{Q}_{\mathrm{k}}\right)$ \\
\hline \multirow{4}{*}{ paraffins (PAR) } & $\mathrm{CH}_{3}$ & 0.9011 & 0.848 & 2.800 & {$[22]$} \\
\hline & $\mathrm{CH}_{2}$ & 0.6744 & 0.540 & 1.900 & {$[22]$} \\
\hline & $\mathrm{CH}$ & 0.4469 & 0.228 & -5.650 & {$[22]$} \\
\hline & $\mathrm{C}$ & 0.2195 & 0.000 & -5.650 & {$[22]$} \\
\hline \multirow{3}{*}{ cycloalkanes (CYC) } & $\mathrm{CH}_{2}$ & 0.6744 & 0.540 & $0.750 * *$ & [22] \\
\hline & $\mathrm{CH}$ & 0.4469 & 0.228 & $0.800 * *$ & [22] \\
\hline & $\mathrm{C}$ & 0.2195 & 0.000 & $0.800 * *$ & {$[22]$} \\
\hline \multirow{2}{*}{ aromatics (ARO) } & $\mathrm{CH}$ & 0.5313 & 0.400 & 0.600 & {$[22]$} \\
\hline & $\mathrm{C}$ & 0.3652 & 0.120 & 0.600 & {$[22]$} \\
\hline methane $\left(\mathrm{CH}_{4}\right)$ & $\mathrm{CH}_{4}$ & 1.1290 & 1.124 & 1.170 & {$[23]$} \\
\hline ethane $\left(\mathrm{C}_{2} \mathrm{H}_{6}\right)$ & $\mathrm{C}_{2} \mathrm{H}_{6}$ & 1.8022 & 1.696 & 1.170 & [22] \\
\hline carbon dioxide $\left(\mathrm{CO}_{2}\right)$ & $\mathrm{CO}_{2}$ & 1.3000 & 0.982 & 1.000 & [23] \\
\hline nitrogen $\left(\mathrm{N}_{2}\right)$ & $\mathrm{N}_{2}$ & 0.8560 & 0.930 & 1.000 & {$[23]$} \\
\hline hydrogen sulphide $\left(\mathrm{H}_{2} \mathrm{~S}\right)$ & $\mathrm{H}_{2} \mathrm{~S}$ & 1.2350 & 1.202 & 1.000 & [23] \\
\hline water* $\left(\mathrm{H}_{2} \mathrm{O}\right)$ & $\mathrm{H}_{2} \mathrm{O}$ & 0.9200 & 1.400 & 1.000 & [22] \\
\hline ethylene glycol* (MEG) & MEG & 3.8888 & 2.248 & 1.000 & {$[22]$} \\
\hline methanol* $(\mathrm{OH})$ & $\mathrm{OH}$ & 1.2711 & 1.152 & 1.000 & {$[22]$} \\
\hline
\end{tabular}

* Polar groups $\quad * *$ Values of $S_{\mathrm{k}}$ for cyclohexane; $S_{\mathrm{k}}=0.5$ for cyclopentane and $=0.9$ for higher cycloalkanes 
Neau et al., Fluid Phase Equilibria, 2016, doi:10.1016/j.fluid.2016.06.035

Table 3a. Values (in J/mol) of the NRTL-PRA group interaction parameters $\Gamma_{L K}^{(0)}$

\begin{tabular}{|c|c|c|c|c|c|c|c|c|c|c|c|}
\hline $\mathbf{L} \backslash \mathbf{K}$ & PAR & CYC & ARO & $\mathrm{CH}_{4}$ & $\mathrm{C}_{2} \mathrm{H}_{6}$ & $\mathrm{CO}_{2}$ & $\mathbf{N}_{2}$ & $\mathbf{H}_{2} \mathrm{~S}$ & $\mathrm{H}_{2} \mathrm{O}$ & MEG & $\mathbf{O H}$ \\
\hline PAR & 0.00 & 41.44 & 220.63 & 147.46 & 48.26 & 866.64 & 523.57 & 733.34 & 2398.94 & 836.31 & $-235.94 *$ \\
\hline CYC & 41.44 & 0.00 & 249.71 & 283.73 & 71.66 & 862.30 & 1035.59 & 731.54 & 2421.64 & 834.63 & $1248.10 * *$ \\
\hline ARO & 220.63 & 249.71 & 0.00 & 555.61 & 552.46 & 820.70 & 1476.84 & 77.16 & 2343.02 & 519.20 & $1596.08 * * *$ \\
\hline $\mathrm{CH}_{4}$ & 147.46 & 283.73 & 555.61 & 0.00 & 73.03 & 748.07 & 231.80 & 1016.15 & 2298.52 & 1281.26 & 1309.96 \\
\hline $\mathbf{C}_{2} \mathbf{H}_{6}$ & 48.26 & 71.66 & 552.46 & 73.03 & 0.00 & 791.11 & 434.38 & 796.08 & 2268.52 & 881.95 & 2275.59 \\
\hline $\mathrm{CO}_{2}$ & 866.64 & 862.30 & 820.70 & 748.07 & 791.11 & 0.00 & 743.75 & 743.35 & 2081.99 & 931.17 & 883.70 \\
\hline $\mathbf{N}_{2}$ & 523.57 & 1035.59 & 1476.84 & 231.80 & 434.38 & 743.75 & 0.00 & 1670.18 & 2518.74 & 2132.21 & 2332.57 \\
\hline $\mathbf{H}_{2} \mathbf{S}$ & 733.34 & 731.54 & 77.16 & 1016.15 & 796.08 & 743.35 & 1670.18 & 0.00 & 2070.29 & 536.39 & -24948.45 \\
\hline $\mathbf{H}_{2} \mathbf{O}$ & 3245.43 & 3140.64 & 2792.91 & 3353.08 & 3302.99 & 2545.63 & 3412.17 & 1711.13 & 0.00 & 124.47 & -1167.86 \\
\hline MEG & 2802.32 & 2768.55 & 2303.47 & 2851.39 & 3239.78 & 1939.87 & 2112.08 & 1110.67 & 124.47 & 0.00 & -476.89 \\
\hline OH & $1535.09 *$ & $2390.22 * *$ & $1555.15^{* * *}$ & 1880.11 & 809.86 & 729.89 & 2092.99 & 1434.23 & -632.34 & -1462.52 & 0.00 \\
\hline
\end{tabular}

PAR : * values for $\Gamma^{(0)} \mathrm{OH} / \mathrm{CH} 3$ and $\Gamma^{(0)} \mathrm{CH} / \mathrm{OH}$

$$
\begin{array}{ll}
\Gamma_{\mathrm{OH} / \mathrm{CH} 2}^{(0)}=2181.15, & \Gamma^{(0)} \mathrm{CH} 2 / \mathrm{OH}=2200.91 \\
\Gamma^{(0)} \mathrm{OH} / \mathrm{CH}=9573.00, & \Gamma^{(0)} \mathrm{CH} / \mathrm{OH}=10290.82
\end{array}
$$

CYC : ** values for $\Gamma^{(0)} \mathrm{OH} / \mathrm{CH} 2$ and $\Gamma^{(0)} \mathrm{CH} / \mathrm{OH}$

$$
\Gamma^{(0)}{ }_{\mathrm{OH} / \mathrm{CH}}=2746.35, \quad \Gamma^{(0)}{ }_{\mathrm{CH} / \mathrm{OH}}=7887.55
$$

$\boldsymbol{A R O}$ : *** values for $\Gamma^{(0)} \mathrm{OH} / \mathrm{CH}$ and $\Gamma^{(0)} \mathrm{CH} / \mathrm{OH}$

$$
\Gamma^{(0)} \mathrm{OH} / \mathrm{C}=1706.49, \quad \Gamma^{(0)} \mathrm{c} / \mathrm{OH}=15362.4
$$


Neau et al., Fluid Phase Equilibria, 2016, doi:10.1016/j.fluid.2016.06.035

Table 3b. Values (in J/mol) of the NRTL-PRA group interaction parameters $\Gamma_{L K}^{(1)}$

\begin{tabular}{|c|c|c|c|c|c|c|c|c|c|c|c|}
\hline $\mathbf{L} \mid \mathbf{K}$ & PAR & CYC & ARO & $\mathbf{C H}_{4}$ & $\mathrm{C}_{2} \mathrm{H}_{6}$ & $\mathrm{CO}_{2}$ & $\mathbf{N}_{2}$ & $\mathrm{H}_{2} \mathrm{~S}$ & $\mathrm{H}_{2} \mathrm{O}$ & MEG & $\mathrm{OH}$ \\
\hline CYC & 71.50 & 0.00 & 191.29 & 294.52 & -172.44 & 524.20 & 1368.42 & 579.77 & -3871.15 & -610.97 & $-5533.53 * *$ \\
\hline ARO & 270.25 & 191.29 & 0.00 & -163.10 & 934.25 & 1491.76 & 1953.96 & -247.07 & -2743.07 & -2048.05 & $-4765.72 * * *$ \\
\hline $\mathbf{C H}_{4}$ & 13.31 & 294.52 & -163.10 & 0.00 & 8.34 & 308.54 & -4.30 & $-166,44$ & $-4350,67$ & $-1033,41$ & $-5857,32$ \\
\hline $\mathrm{CO}_{2}$ & 609.92 & 524.20 & 1491.76 & 308.54 & 529.51 & 0.00 & 165.41 & -368.65 & -4055.83 & -2214.13 & -10885.41 \\
\hline $\mathbf{N}_{2}$ & 59.69 & 1368.42 & 1953.96 & -4.30 & -18.84 & 165.41 & 0.00 & -171.30 & -4778.13 & -3011.62 & -3933.10 \\
\hline $\mathbf{H}_{2} \mathrm{~S}$ & -227.72 & 579.77 & -247.07 & -166.44 & 120.77 & -368.65 & -171.30 & 0.00 & -1531.87 & -643.68 & -26517.61 \\
\hline $\mathrm{H}_{2} \mathrm{O}$ & -294.87 & -285.83 & -879.36 & -895.00 & -808.34 & -234.88 & -665.51 & -2658.09 & 0.00 & -718.30 & -1235.62 \\
\hline
\end{tabular}

PAR : * values for $\Gamma^{(1)} \mathrm{OH} / \mathrm{CH} 3$ and $\Gamma^{(1)} \mathrm{CH} / \mathrm{OH}$ :

$$
\begin{aligned}
& \Gamma^{(1)}{ }_{\text {OH/CH }}=-37.35, \quad \Gamma^{(1)} \mathrm{CH} / \mathrm{OH}=-92.72 \\
& \Gamma^{(1)} \mathrm{OH} / \mathrm{CH}=-201.30, \quad \Gamma^{(1)} \mathrm{CH/OH}=-152.30
\end{aligned}
$$

CYC : ** values for $\Gamma^{(1)} \mathrm{OH} / \mathrm{CH} 2$ and $\Gamma^{(1)} \mathrm{CH} / \mathrm{OH}$

$$
\Gamma^{(1)} \mathrm{OH} / \mathrm{CH}=416.03 \quad, \quad \Gamma^{(1)} \mathrm{CH} / \mathrm{OH}=41576.08
$$

ARO : *** values for $\Gamma^{(1)} \mathrm{OH} / \mathrm{CH}$ and $\Gamma^{(1)} \mathrm{CH} / \mathrm{OH}$

$\Gamma^{(1)}{ }_{\text {OH/C }}=8046,30, \quad \Gamma^{(1)} \mathrm{CIOH}=1558,89$ 
Table 3c. Values (in J/mol) of the NRTL-PRA group interaction parameters $\Gamma_{L K}^{(2)}$

\begin{tabular}{crrr}
\hline $\mathbf{L I K}$ & $\mathbf{H}_{\mathbf{2}} \mathbf{O}$ & MEG & $\mathbf{O H}$ \\
\hline $\mathbf{H}_{\mathbf{2}} \mathbf{O}$ & 0.00 & 0.00 & -327.10 \\
$\mathbf{M E G}$ & 0.00 & 0.00 & 65.82 \\
$\mathbf{O H}$ & -327.10 & -1036.95 & 0.00 \\
\hline
\end{tabular}


Table 4a. Modeling of VLE, $\mathrm{h}^{\mathrm{E}}$ and LLE for mixtures containing methanol (component ${ }^{(1)}$ ) and paraffins or cycloalkanes. Comparison of results obtained with : (I) «NRTL-PRA » and (II) «NRTL-PR» EoS. Representation of experimental data : number of data points $\left(N_{V L E}, N_{h E,}, N_{x 1} N_{x 2}\right)$, maximum temperature $T_{\max }(\mathrm{K})$ and pressure $P_{\max }(\mathrm{MPa})$, deviations $(\Delta P / P \%)$ on pressure, $\left(\Delta h^{E} / h^{E} \%\right)$ on excess enthalpies and $\left(\Delta x_{1} / x_{1} \%,, \Delta x_{2} / x_{2} \%\right)$ on the mole fractions respectively in the «hydrocarbon » and «methanol» rich phases.

\begin{tabular}{|c|c|c|c|c|c|c|c|c|c|c|c|c|c|c|c|}
\hline \multirow{2}{*}{ Component $^{(2)}$} & \multirow[b]{2}{*}{$N_{V L E}$} & \multirow[b]{2}{*}{$T_{\max }$} & \multicolumn{2}{|c|}{$\triangle P / P \%$} & \multirow[b]{2}{*}{$N_{h E}$} & \multirow[b]{2}{*}{$T_{\max }$} & \multicolumn{2}{|c|}{$\Delta h^{E} / h^{E} \%$} & \multirow[b]{2}{*}{$\boldsymbol{P}_{\max }$} & \multirow[b]{2}{*}{$N_{x 1}$} & \multicolumn{2}{|c|}{$\Delta x_{1} / x_{1} \%$} & \multirow[b]{2}{*}{$N_{x 2}$} & \multicolumn{2}{|c|}{$\Delta x_{2} / x_{2} \%$} \\
\hline & & & $(I)$ & (II) & & & $(I)$ & (II) & & & (I) & $(I I)$ & & (I) & (II) \\
\hline Propane & 77 & 474 & 25.86 & 23.01 & 415 & 373 & 20.90 & 13.27 & - & - & - & - & - & - & - \\
\hline Butane & 106 & 470 & 17.64 & 18.86 & 177 & 348 & 30.25 & 9.29 & 10 & 17 & 22.51 & 93.99 & 21 & 75.49 & 41.20 \\
\hline Pentane & 104 & 423 & 9.21 & 10.04 & 293 & 363 & 64.49 & 45.69 & 40 & 39 & 21.25 & 90.46 & 36 & 39.35 & 38.24 \\
\hline Hexane & 504 & 448 & 6.06 & 9.30 & 154 & 323 & 59.31 & 52.49 & 40 & 158 & 15.70 & 82.28 & 150 & 16.07 & 33.15 \\
\hline Heptane & 127 & 339 & 4.05 & 12.11 & 119 & 333 & 62.78 & 55.10 & 40 & 120 & 29.03 & 77.87 & 82 & 14.92 & 59.53 \\
\hline Octane & 50 & 368 & 9.86 & 19.55 & - & - & - & - & 40 & 74 & 36.73 & 76.64 & 87 & 19.77 & 67.57 \\
\hline Nonane & - & - & - & - & - & - & - & - & 0.2 & 11 & 13.37 & 79.46 & 9 & 62.54 & 28.96 \\
\hline Decane & 29 & 409 & 42.65 & 51.94 & 21 & 298 & 253.46 & 156.57 & 40 & 36 & 57.94 & 74.32 & 32 & 19.85 & 194.29 \\
\hline Undecane & 18 & 429 & 130.56 & 147.79 & - & - & - & - & 0.101 & 4 & 88.59 & 42.69 & 4 & 12.25 & 580.70 \\
\hline Dodecane & - & - & - & - & - & - & - & - & 0.101 & 4 & 89.30 & 39.17 & 4 & 9.65 & 827.12 \\
\hline 2-m Propane & 113 & 423 & 19.82 & 260.62 & - & - & - & - & - & - & - & - & - & - & - \\
\hline 2-m Butane & 46 & 319 & 2.98 & 11.47 & - & - & - & - & - & - & - & - & - & - & - \\
\hline 2,3-m Butane & 60 & 333 & 2.10 & 8.75 & - & - & - & - & - & - & - & - & - & - & - \\
\hline 2-m Pentane & 6 & 321 & 5.91 & 10.38 & - & - & - & - & - & - & - & - & - & - & - \\
\hline 3-m Pentane & 5 & 330 & 7.57 & 9.56 & - & - & - & - & - & - & - & - & - & - & - \\
\hline 2,2,4-m Pentane & 31 & 341 & 14.26 & 10.74 & - & - & - & - & 120 & 10 & 43.45 & 86.89 & 12 & 100.00 & 44.22 \\
\hline Cyclopentane & - & - & - & - & - & - & - & - & 0.101 & - & - & - & 3 & 11.29 & 35.78 \\
\hline m-Cyclopentane & 51 & 345 & 10.30 & 13.39 & - & - & - & - & 0.101 & - & - & - & 6 & 3.00 & 19.16 \\
\hline Cyclohexane & 464 & 354 & 6.85 & 11.30 & 185 & 323 & 49.84 & 86.63 & 0.101 & 60 & 26.99 & 18.49 & 46 & 17.12 & 18.43 \\
\hline m-Cyclohexane & 37 & 336 & 8.44 & 13.02 & 45 & 313 & 172.12 & 119.03 & 0.101 & 13 & 7.90 & 45.73 & 22 & 5.82 & 21.17 \\
\hline Cyclooctane & - & - & - & - & - & - & - & - & 0.101 & 28 & 29.46 & 50.31 & 18 & 23.92 & 31.76 \\
\hline Global & 1828 & & 10.67 & 29.29 & 1409 & & $\mathbf{5 0 . 9 7}$ & 42.48 & & 574 & 27.56 & 71.43 & 532 & 23.01 & 61.51 \\
\hline
\end{tabular}


Table 4b. Modeling of VLE and $\mathrm{h}^{\mathrm{E}}$ for mixtures containing methanol (component ${ }^{(1)}$ ) and aromatics, light gases and associating components. Comparison of results obtained with : $(I)$ «NRTL-PRA» and $(I I)$ «NRTL-PR» EoS . Representation of experimental data : number of data points $\left(N_{V L E}, N_{h E}\right)$, maximum temperature $T_{\max }(\mathrm{K})$, deviations $(\Delta P / P \%)$ on pressure and $\left(\Delta h^{E} / h^{E} \%\right)$ on excess enthalpies.

\begin{tabular}{|c|c|c|c|c|c|c|c|c|}
\hline \multirow{2}{*}{ Component $^{(2)}$} & \multirow[b]{2}{*}{$N_{V L E}$} & \multirow[b]{2}{*}{$T_{\max }$} & \multicolumn{2}{|c|}{$\triangle P / P \%$} & \multirow[b]{2}{*}{$N_{h E}$} & \multirow[b]{2}{*}{$T_{\max }$} & \multicolumn{2}{|c|}{$\Delta h^{E} / h^{E} \%$} \\
\hline & & & (I) & (II) & & & (I) & (II) \\
\hline Benzene & 243 & 493 & 3.81 & 2.67 & 39 & 318 & 12.73 & 16.14 \\
\hline Toluene & 257 & 382 & 9.02 & 5.75 & 35 & 308 & 10.62 & 17.12 \\
\hline Ethyl benzene & 13 & 409 & 2.43 & 6.03 & - & - & - & - \\
\hline o-Xylene & 35 & 415 & 12.77 & 12.66 & - & - & - & - \\
\hline m-Xylene & 13 & 412 & 3.64 & 5.95 & - & - & - & - \\
\hline p-Xylene & 66 & 412 & 11.76 & 10.16 & 58 & 298 & 11.39 & 15.55 \\
\hline 1,3,5-m Benzene & - & - & - & - & 12 & 298 & 10.71 & 13.77 \\
\hline Methane & 94 & 373 & 27.86 & 35.04 & & & & \\
\hline Ethane & 45 & 373 & 5.44 & 4.56 & 221 & 348 & 41.02 & 55.74 \\
\hline Nitrogen & 189 & 373 & 17.78 & 13.37 & & & & \\
\hline Hydrogen sulfide & 80 & 448 & 2.92 & 2.67 & & & & \\
\hline Carbon dioxide & 210 & 473 & 13.72 & 14.21 & 275 & 573 & 27.46 & 28.57 \\
\hline Water & 1211 & 548 & 2.21 & 2.32 & 612 & 573 & 12.42 & 11.34 \\
\hline Ethylene glycol & 69 & 462 & 7.08 & 6.97 & 70 & 323 & 3.23 & 4.25 \\
\hline Global & 2525 & & 6.75 & 6.30 & 1322 & & 19.74 & 22.47 \\
\hline
\end{tabular}



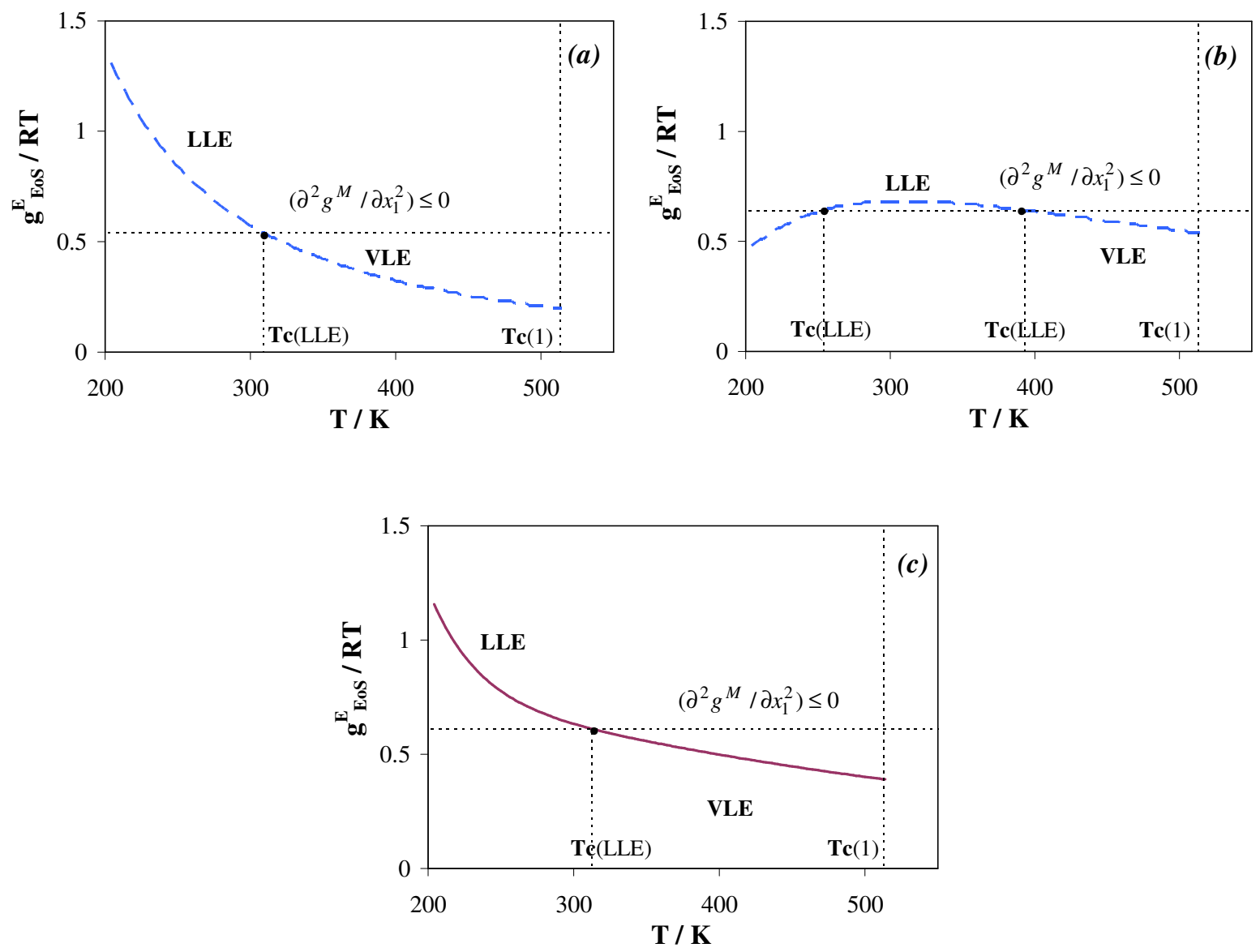

Figure 1. Methanol ${ }^{(1)}-$ hexane $^{(2)}$ system. Excess Gibbs energy $g_{E o S}^{E} / R T$ (see Table 1) calculated for $x=0.5$ as a function of temperature, respectively for: NRTL-PR EOS (- ), with: $g_{E O S}^{E}=g_{\text {res }}^{E}$ and NRTL-PRAEOS (—), with: $g_{\text {EoS }}^{E}=g_{\text {diss }}^{E}+g_{\text {res }}^{E}$. 


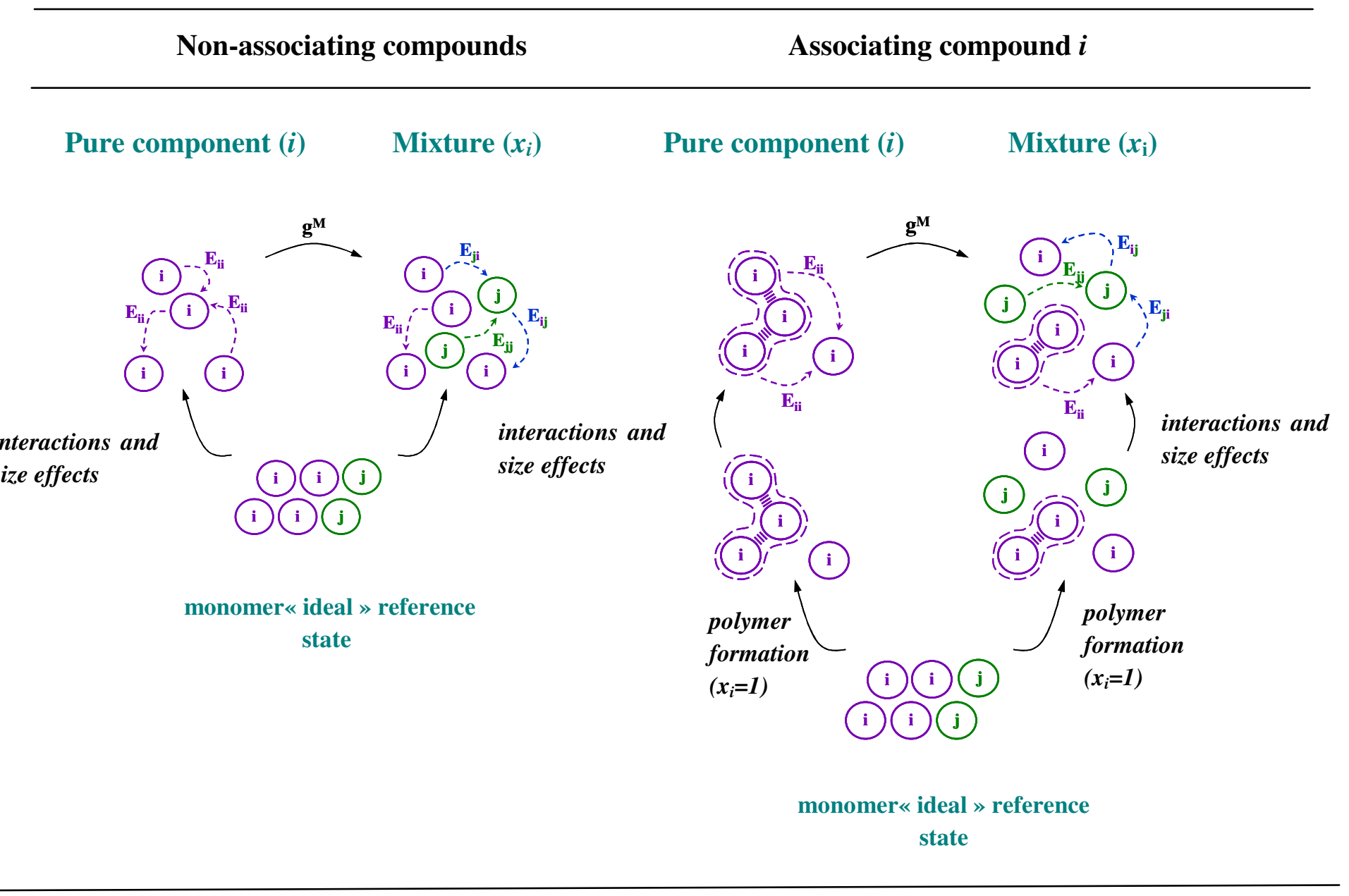

Figure 2. Illustration of the free energy of mixing $g^{M}$ for a mixture of non-associating compounds and for a mixture containing one associating compound. 

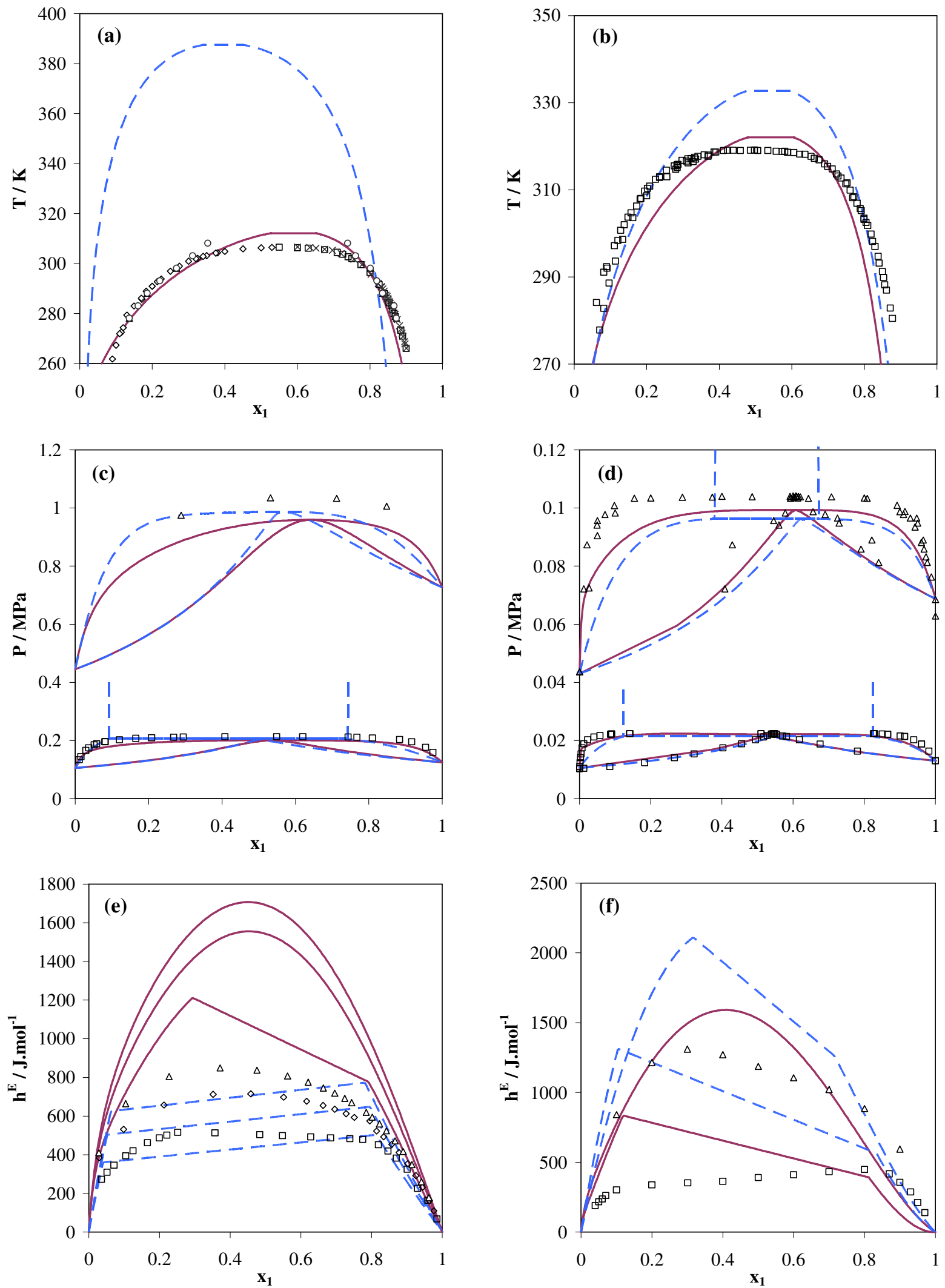

Figure 3. Methanol ${ }^{(1)}$ with paraffins ${ }^{(2)}$ and cycloalkanes ${ }^{(2)}$. Simultaneous prediction of LLE, VLE and $\mathrm{h}^{\mathrm{E}}$ with the NRTL-PRA (-) and the NRTL-PR $(--)$ EoS. (a) Hexane ${ }^{(2)}$ : LLE under P = 0.101 MPa [32-34]. (b) Cyclohexane $^{(2)}$ : LLE under $\mathrm{P}=0.101 \mathrm{MPa}$ [35-37]. (c) Hexane ${ }^{(2)}$ : VLE at $(\square) \mathrm{T}=343 \mathrm{~K}$ [38] and $(\Delta) \mathrm{T}=$ $398 \mathrm{~K}$ [39]. (d) Cyclohexane ${ }^{(2)}$ : VLE at $(\square) \mathrm{T}=293 \mathrm{~K}[40]$ and $(\Delta) \mathrm{T}=328 \mathrm{~K}$ [41-44]. (e) Hexane ${ }^{(2)}: h^{E}$ under $\mathrm{P}=0.2 \mathrm{MPa}$ and at $(\square) \mathrm{T}=298 \mathrm{~K}[45],(\diamond) \mathrm{T}=313 \mathrm{~K}[45]$ and $(\Delta) \mathrm{T}=323 \mathrm{~K}[45] .(f)$ Cyclohexane $^{(2)}$ : $\mathrm{h}^{\mathrm{E}}$ under $\mathrm{P}=0.2 \mathrm{MPa}$ and at $(\square) \mathrm{T}=288 \mathrm{~K}[46]$ and $(\Delta) \mathrm{T}=323 \mathrm{~K}$ [47]; straight lines represent the two phase regions. 

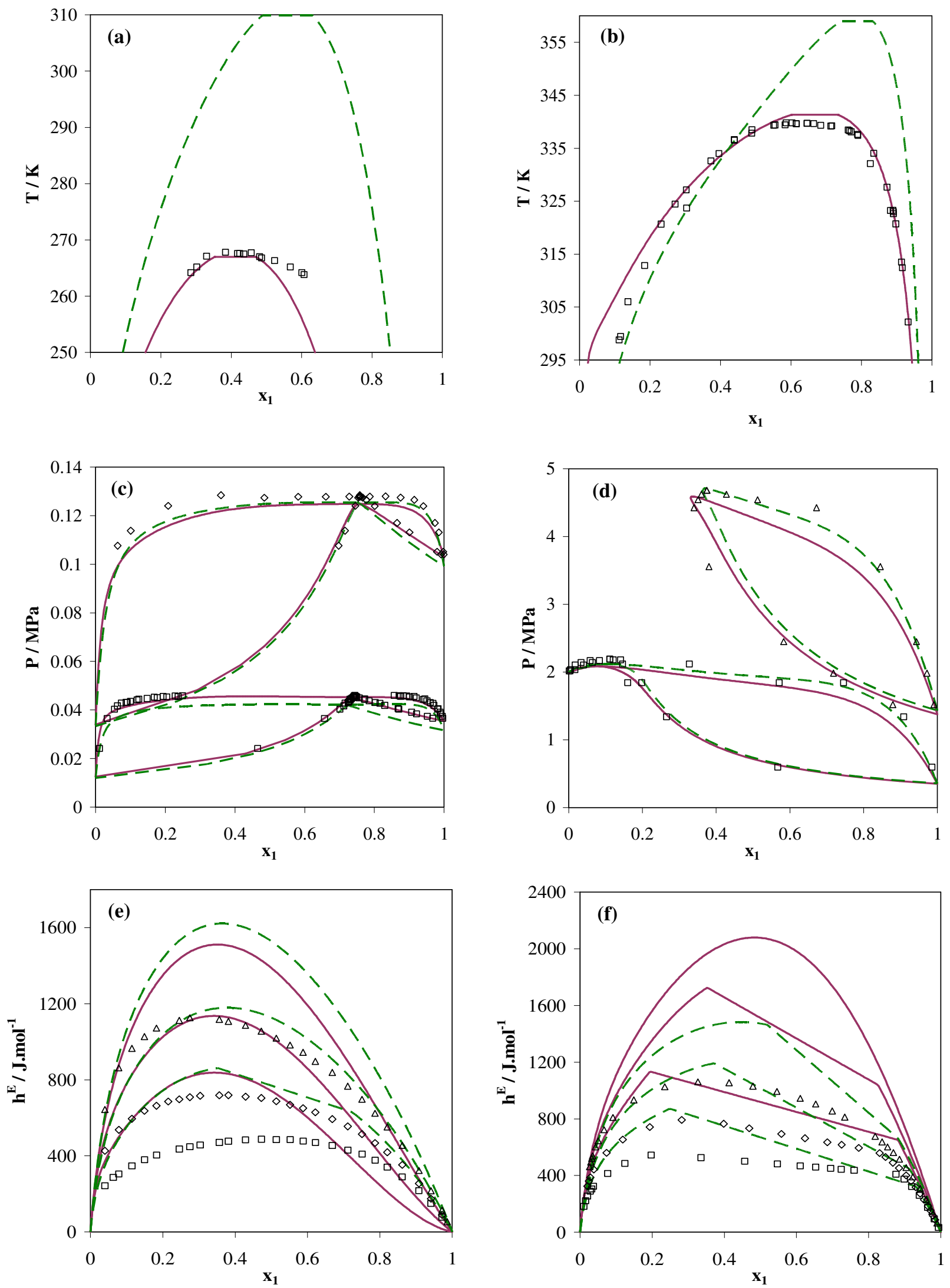

Figure 4. Methanol ${ }^{(1)}$-paraffins ${ }^{(2)}$ systems. Prediction of LLE, VLE and $\mathrm{h}^{\mathrm{E}}$ with the NRTL-PRA $(-)$ and the VTPR (- - ) equations. (a) Butane ${ }^{(2)}$ : LLE at ( $\left.\square\right) \mathrm{P}=5 \mathrm{MPa}[48]$. (b) Octane ${ }^{(2)}$ : LLE at ( $\left.\square\right) \mathrm{P}=1 \mathrm{MPa}$ [49, 50]]. (c) Heptane ${ }^{(2)}$ : VLE at $(\square) \mathrm{T}=313 \mathrm{~K}$ [51,52] and $(\diamond) \mathrm{T}=338 \mathrm{~K}$ [53]. (d) 2-Methylpropane ${ }^{(2)}$ : VLE at $(\square) \mathrm{T}=373 \mathrm{~K}[54]$ and $(\Delta) \mathrm{T}=423 \mathrm{~K}$ [54]. $(e)$ Butane $^{(2)}: \mathrm{h}^{\mathrm{E}}$ under $\mathrm{P}=5 \mathrm{MPa}$ and at $(\square) \mathrm{T}=298 \mathrm{~K}[55]$, $(\diamond) \mathrm{T}=323 \mathrm{~K}[55]$ and $(\Delta) \mathrm{T}=348 \mathrm{~K}[55] .(f)$ Heptane $^{(2)}: \mathrm{h}^{\mathrm{E}}$ under $\mathrm{P}=0.2 \mathrm{MPa}$ and at $(\square) \mathrm{T}=303 \mathrm{~K}[45]$, $(\diamond) \mathrm{T}=318 \mathrm{~K}[45]$ and $(\Delta) \mathrm{T}=333 \mathrm{~K}$ [45]; straight lines represent the two phase regions. 

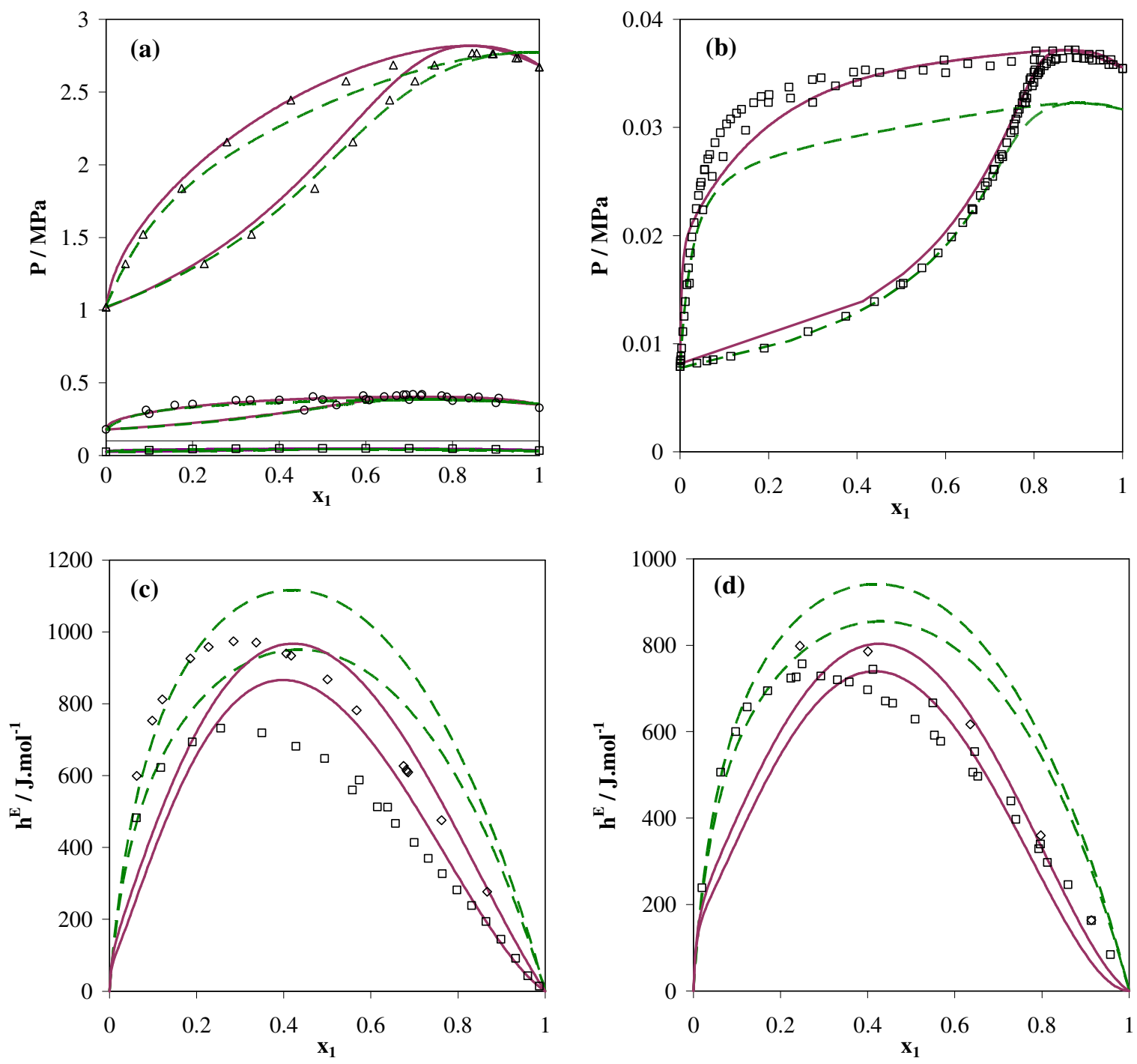

Figure 5. Methanol ${ }^{(1)}$-aromatics ${ }^{(2)}$ systems. Prediction of VLE and $h^{\mathrm{E}}$ with the NRTL-PRA $(-)$ and the VTPR ( -- ) equations. (a) Benzene ${ }^{(2)}$ : VLE at ( $\square$ ) $\mathrm{T}=313 \mathrm{~K} \mathrm{[56],} \mathrm{( \circ )} \mathrm{T}=373 \mathrm{~K} \mathrm{[57]}$ and $(\Delta) \mathrm{T}=453 \mathrm{~K}$ [57]. (b) Toluene ${ }^{(2)}$ : VLE at $(\square) \mathrm{T}=313 \mathrm{~K}[58,59]$. (c) Benzene ${ }^{(2)}: \mathrm{h}^{\mathrm{E}}$ under $\mathrm{P}=0.101 \mathrm{MPa}$ and at $(\square) \mathrm{T}=$ $298 \mathrm{~K}[60]$ and $(\diamond) \mathrm{T}=318 \mathrm{~K}[61] .(d)$ Toluene $^{(2)}: \mathrm{h}^{\mathrm{E}}$ under $\mathrm{P}=0.101 \mathrm{MPa}$ and at $(\square) \mathrm{T}=298 \mathrm{~K}[62,63]$ and $(\diamond) \mathrm{T}=308 \mathrm{~K}[62]$. 

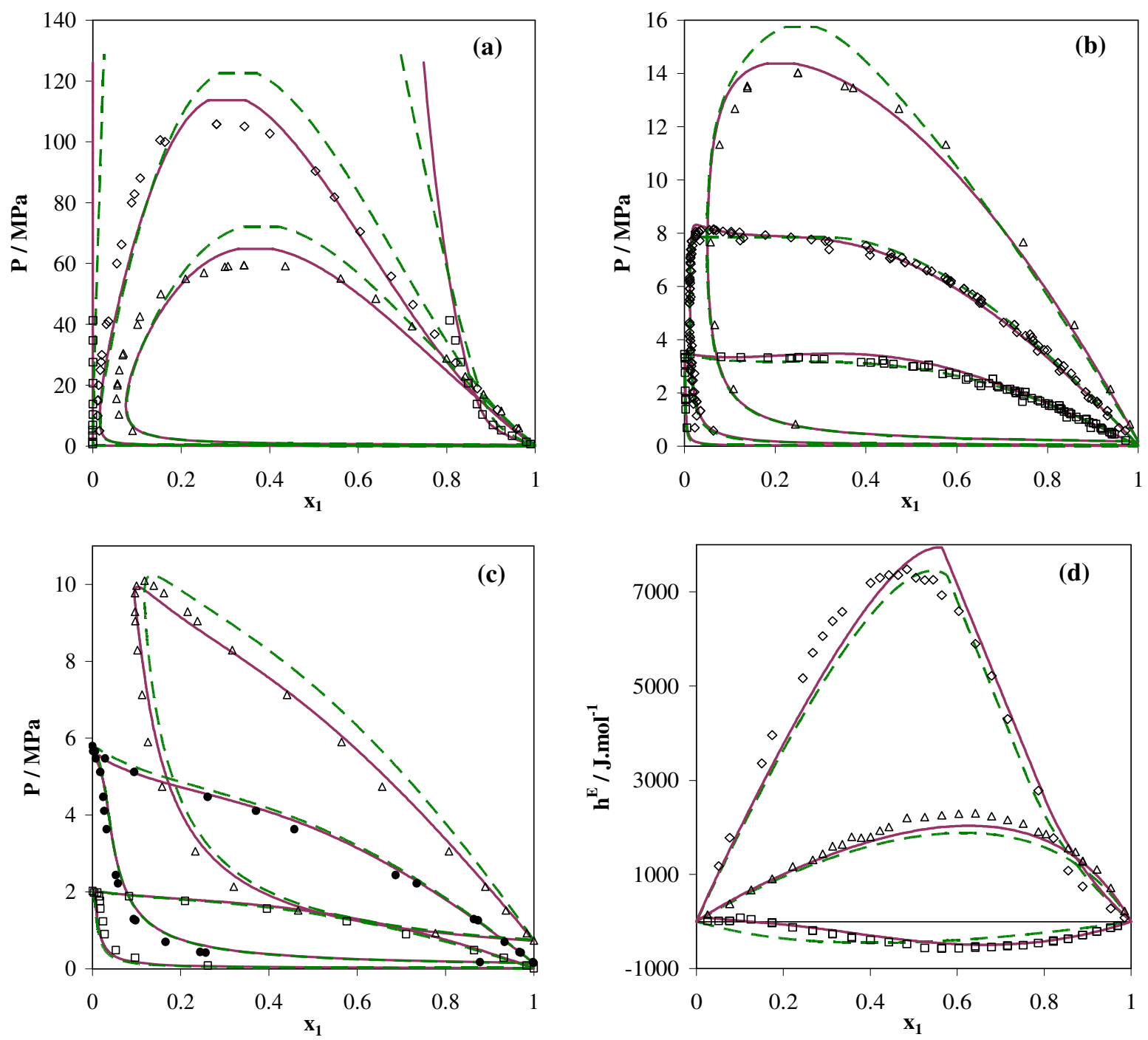

Figure 6. Methanol ${ }^{(1)}$-light gases ${ }^{(2)}$ systems. Prediction of VLE and $h^{\mathrm{E}}$ with the NRTL-PRA $(-)$ and the VTPR ( - - ) equations. (a) Methane ${ }^{(2)}$ : VLE at $(\square) \mathrm{T}=220 \mathrm{~K}[64],(\diamond) \mathrm{T}=323 \mathrm{~K}[65]$ and $(\Delta) \mathrm{T}=373 \mathrm{~K}$ [65]. (b) Carbon dioxide ${ }^{(2)}$ : VLE at $(\square) \mathrm{T}=273 \mathrm{~K}$ [66-70], $(\diamond) \mathrm{T}=313 \mathrm{~K}$ [71-75] and $(\Delta) \mathrm{T}=352 \mathrm{~K}$ [76]. (c) Hydrogen sulfide ${ }^{(2)}$ : VLE at $(\square) \mathrm{T}=298 \mathrm{~K}$ [77], $(\bullet) \mathrm{T}=348 \mathrm{~K}$ [77] and $(\Delta) \mathrm{T}=398 \mathrm{~K}$ [77]. (d) Carbon

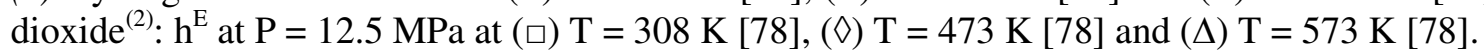



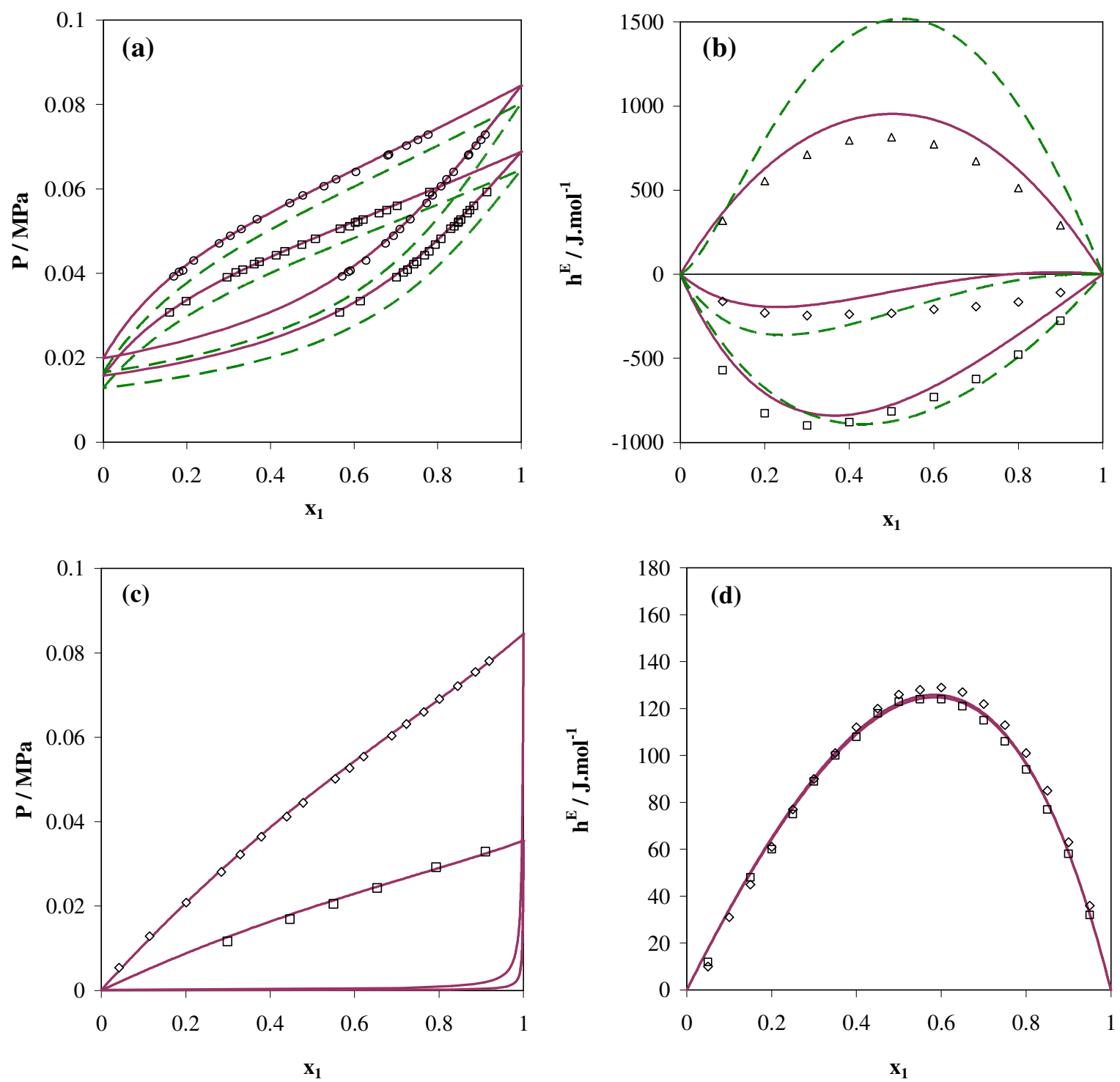

Figure 7. Methanol ${ }^{(1)}$ - associating compounds ${ }^{(2)}$ systems. Prediction of VLE and $\mathrm{h}^{\mathrm{E}}$ with the NRTL-PRA ( $\longrightarrow$ ) and the VTPR (- - ) equations. (a) Water ${ }^{(2)}$ : VLE at ( $\left.\square\right) \mathrm{T}=328 \mathrm{~K}$ [79] and (०) T=333 K [79]. (b) Water $^{(2)}: \mathrm{h}^{\mathrm{E}}$ under $\mathrm{P}=20 \mathrm{MPa}$ at $(\square) \mathrm{T}=298 \mathrm{~K}[80],(\diamond) \mathrm{T}=373 \mathrm{~K}[80]$ and $(\Delta) \mathrm{T}=523 \mathrm{~K}[80] .(c)$ Ethylene glycol ${ }^{(2)}$ : VLE at $(\square) \mathrm{T}=313 \mathrm{~K}[81]$ and $(\diamond) \mathrm{T}=333 \mathrm{~K}[82] .(d)$ Ethylene glycol ${ }^{(2)}: \mathrm{h}^{\mathrm{E}}$ under $\mathrm{P}=0.1$ MPa at $(\square) \mathrm{T}=298 \mathrm{~K}[83]$ and $(\diamond) \mathrm{T}=308 \mathrm{~K}[83]$. 

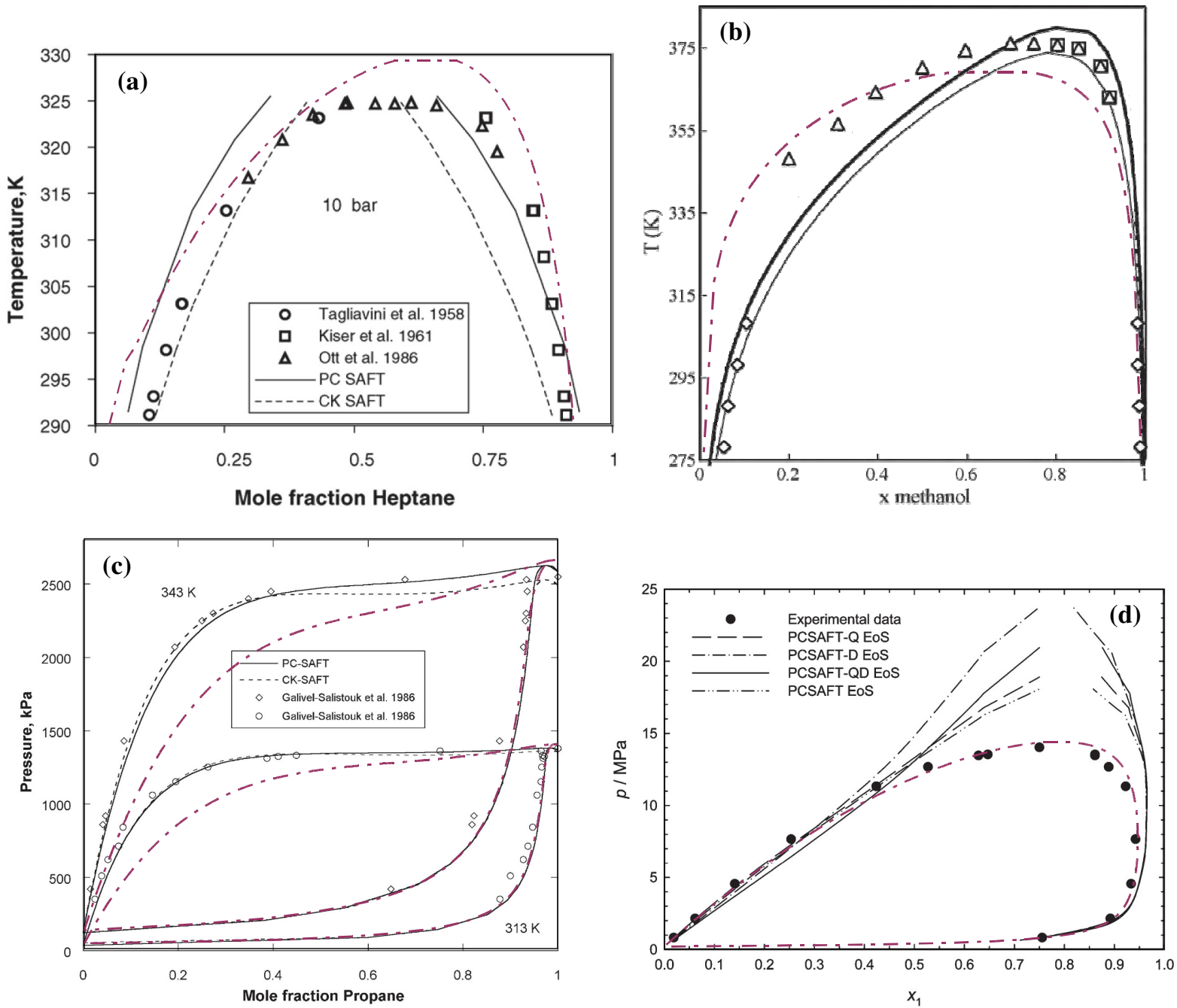

Figure 8. Methanol ${ }^{(1)}$ with paraffins ${ }^{(2)}$ and light gases $^{(2)}$. Prediction of LLE and VLE with NRTL-PRA (- : -) and PC-SAFT $(-)$ equations. (a) Heptane ${ }^{(2)}$ : LLE under $\mathrm{P}=1 \mathrm{MPa}$ (SAFT curves from [4]). (b) Undecane $^{(2)}$ : LLE under $\mathrm{P}=2 \mathrm{MPa}$ (SAFT curves from [6]). (c) Propane ${ }^{(2)}$ : VLE at $(\circ) \mathrm{T}=313 \mathrm{~K}$ and $(\diamond) \mathrm{T}$ $=343 \mathrm{~K}$ (SAFT curves from [4]). (d) Carbon dioxide ${ }^{(2)}$ : VLE at $\mathrm{T}=353 \mathrm{~K}$ (SAFT curves from [5]). 

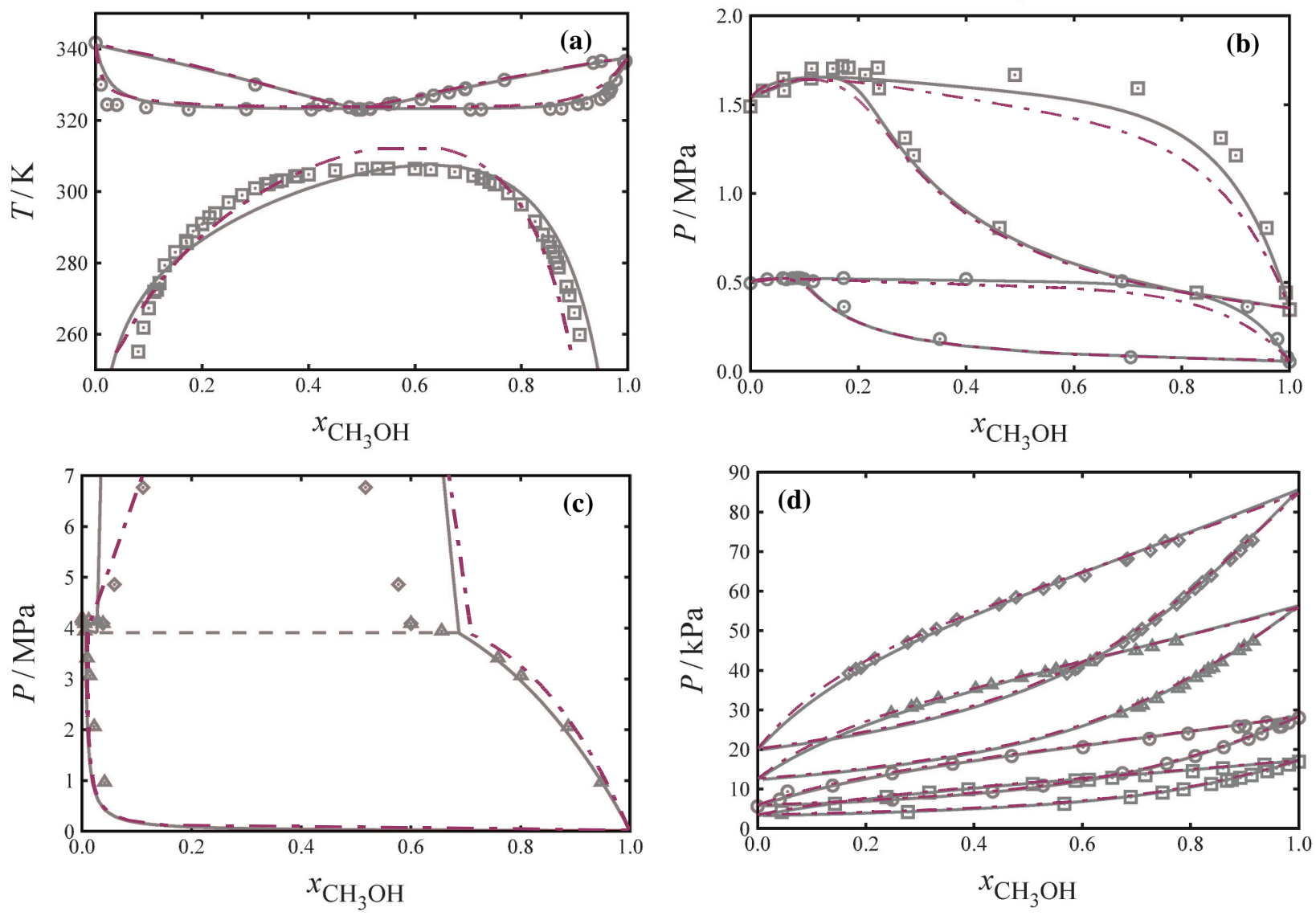

Figure 9. Methanol ${ }^{(1)}$ with paraffins ${ }^{(2)}$, light gases $^{(2)}$ and associating compounds ${ }^{(2)}$. Prediction of phase equilibria with the NRTL-PRA EoS $(-\cdot-)$ and the curves [7] from the SAFT- $\gamma$ Mie equation $(-)$ ).

(a) Hexane ${ }^{(2)}$ : (口) LLE and (०) VLE under P = 0.101 MPa. (b) Butane ${ }^{(2)}$ : VLE at (०) $\mathrm{T}=323 \mathrm{~K}$ and ( $\square$ ) $\mathrm{T}=$ 373 K. (c) Ethane ${ }^{(2)}:(\Delta)$ VLE and $(\diamond)$ LLE at $\mathrm{T}=298 \mathrm{~K} .(d)$ Water $^{(2)}$ : VLE at $(\square) \mathrm{T}=298 \mathrm{~K},(\circ) \mathrm{T}=308 \mathrm{~K}$, $(\Delta) \mathrm{T}=323 \mathrm{~K}$ and $(\diamond) \mathrm{T}=333 \mathrm{~K}$. 